\title{
Contributions of soil moisture interactions to future precipitation changes in the GLACE-CMIP5 experiment
}

\author{
Wilhelm May ${ }^{1,2}$ (1) $\cdot$ Markku Rummukainen ${ }^{1} \cdot$ Frederique Chéruy $^{3} \cdot$ \\ Stefan Hagemann ${ }^{4} \cdot$ Arndt Meier $^{1}$
}

Received: 23 May 2016 / Accepted: 15 October 2016 / Published online: 25 October 2016

(C) The Author(s) 2016. This article is published with open access at Springerlink.com

\begin{abstract}
Changes in soil moisture are likely to contribute to future changes in latent heat flux and various characteristics of daily precipitation. Such contributions during the second half of the twenty-first century are assessed using the simulations from the GLACE-CMIP5 experiment, applying a linear regression analysis to determine the magnitude of these contributions. As characteristics of daily precipitation, mean daily precipitation, the frequency of wet days and the intensity of precipitation on wet days are considered. Also, the frequency and length of extended wet and dry spells are studied. Particular focus is on the regional (for nine selected regions) as well as seasonal variations in the magnitude of the contributions of the projected differences in soil moisture to the future changes in latent heat flux and in the characteristics of daily precipitation. The results reveal the overall tendency that the projected differences in soil moisture contribute to the future changes in response to the anthropogenic climate forcing for all the meteorological variables considered here. These contributions are stronger and more robust (i.e., there are smaller deviations between individual climate models) for the latent heat flux than for the characteristics of daily precipitation. It is also found that the contributions of the differences in soil moisture to the future changes are generally
\end{abstract}

Wilhelm May

wilhelm.may@cec.lu.se

1 Centre for Environmental and Climate Research, Lund University, Sölvegatan 37, 22362 Lund, Sweden

2 Research and Development Department, Danish Meteorological Institute, Copenhagen, Denmark

3 CNRS/IPSL/LMD, University Pierre and Marie Curie, Paris, France

4 Max-Planck-Institute for Meteorology, Hamburg, Germany stronger and more robust for the frequency of wet days than for the intensity of daily precipitation. Consistent with the contributions of the projected differences in soil moisture to the future changes in the frequency of wet days, soil moisture generally contributes to the future changes in the characteristics of wet and dry spells. The magnitude of these contributions does not differ systematically between the frequency and the length of such extended spells, but the contributions are generally slightly stronger for dry spells than for wet spells. Distinguishing between the nine selected regions and between the different seasons, it is found that the strength of the contributions of the differences in soil moisture to the future changes in the various meteorological variables varies by region and, in particular, by season. Similarly, the robustness of these contributions varies between the regions and in the course of the year. The importance of soil moisture changes for the future changes in various aspects of daily precipitation and other aspects of the hydrological cycle illustrates the need for a comprehensive and realistic representation of land surface processes and of land surface conditions in climate models.

Keywords Climate change - Soil moisture - Soil moistureprecipitation coupling $\cdot$ Frequency of wet days $\cdot$ Intensity of daily precipitation $\cdot$ Wet spells $\cdot$ Dry spells

\section{Introduction}

Interactions between soil moisture and precipitation and between soil moisture and temperature have profound effects on the water and energy cycles. Soil moisture affects the partition between latent and sensible heat fluxes at the surface and, by this, air temperature, boundary layer stability and in some instances precipitation. Seneviratne 
et al. (2010) introduced a conceptual framework for the soil moisture-precipitation coupling and feedback, comprising of three links: first, a relationship between soil moisture anomalies and subsequent evapotranspiration anomalies, second, a relationship between evapotranspiration anomalies and subsequent precipitation anomalies and, finally, a relationship between precipitation anomalies and resulting soil moisture anomalies. The first two connections constitute the soil moisture-precipitation coupling and the full loop with all the three components the soil moisture-precipitation feedback. For the third link, increasing precipitation generally causes increased soil moisture. Exceptions are precipitation over wet and saturated soils, for which increased precipitation leads to additional runoff rather than soil moisture, or cases of intense precipitation, when precipitation exceeds the infiltration rate, again resulting in additional runoff rather than soil moisture (e.g., Bras 1990). Under extreme drought conditions, on the other hand, soils may have cracks in which precipitation infiltrates and, thus, bypasses the surface zone (e.g., Hillel 1998). The first relationship is generally positive, with higher soil moisture leading to stronger evapotranspiration. The positive effect on evaporation is particularly strong in transitional zones between dry and wet climates (Seneviratne et al. 2010). The direction of the second step, however, is the most uncertain as several physical processes are involved. Many modelling studies have investigated this issue. A large number of these studies have identified a positive relationship between enhanced soil moisture and evaporation on one side and precipitation on the other (e.g., Schär et al. 1999; Pal and Eltahir 2001; Koster et al. 2004). However, the physical processes involved are very complex, and several further modelling studies suggested that under specific conditions convective instability and/or cloud formation might be stronger over dry soils (e.g., Findell and Eltahir 2003; Ek and Holtslag 2004; Hohenegger et al. 2009).

Studies on the coupling of precipitation to soil moisture or evapotranspiration have given mixed results on the sign of the coupling. In their pioneering study, Koster et al. (2004) found a strong positive coupling of precipitation to soil moisture in boreal summer in various parts of the Northern Hemisphere, i.e., the southern part of North America, Western Africa and central India. The strength of this coupling, however, varied considerably between the 12 global climate models, which contributed to the study. Consistent with this, Findell et al. (2011) diagnosed a strong positive coupling between evapotranspiration and afternoon showers in the eastern United States and Mexico from observations. In particular, they found marked increases in the probability of afternoon showers caused by variations of the surface fluxes in these regions, while the intensity of rainfall was largely insensitive to the variations of the surface fluxes. Taylor et al. (2012a), on the other hand, found for Western Africa that afternoon rainfall preferably falls over soils that are relatively dry compared to the surrounding area based on observations. But only one of the six global weather and climate models considered in that study reproduced this behaviour. Recently, Guillod et al. (2015) was able to reconcile the contrasting results on the impacts of soil moisture on afternoon rainfall by distinguishing between the spatial and the temporal effects of soil moisture. They showed that afternoon precipitation tends to occur during wet heterogeneous soil moisture conditions, while being located over comparatively drier areas.

The GLACE-CMIP5 experiment was designed to investigate the impacts of soil moisture on the long-term changes in climate (Seneviratne et al. 2013). "GLACE" refers to the Global Land-Atmosphere Coupling Experiment (Koster et al. 2004, 2010) and "CMIP5" to the fifth phase of the Coupled Model Intercomparison Project (Taylor et al. 2012b). A number of studies have analysed the simulations from the GLACE-CMIP5 experiment, focussing on different research questions (see Table 1 for an overview). Seneviratne et al. (2013) presented first results on the impact of the projected differences in soil moisture on changes in, among others, near-surface temperatures and precipitation by the end of the twenty-first century. They found a substantial and consistent effect on temperatures in several parts of the globe and some influence on precipitation in the Northern Hemisphere extratropics during summer. That study was complemented by May et al. (2015), who quantified the contributions of the projected differences in soil moisture to the future changes in various aspects of near-surface climate in the tropics by the end of the twenty-first century by means of linear regression analysis. They found that the projected changes in soil moisture give important contributions to the climate change in the tropics. This is particularly the case for the surface energy fluxes as well as for near-surface temperatures but to a much lesser extent for precipitation. Lorenz et al. (2016) analysed the influence of both soil moisture variability and trends in the second half of the twenty-first century on various extremes related to daily maximum temperatures and daily precipitation. According to their results, removing the soil moisture variability significantly reduces temperature extremes over most of the global land areas, while wet precipitation extremes are enhanced in the tropics. Projected future drying trends in soil moisture, on the other hand, were found to lead to increases in temperature extremes in the second half of the twenty-first century, while wet precipitation extremes are decreased in the tropics, and dry extremes are enhanced in some regions. Finally, Berg et al. (2016) showed that global aridity is enhanced by the feedbacks of the projected soil moisture 


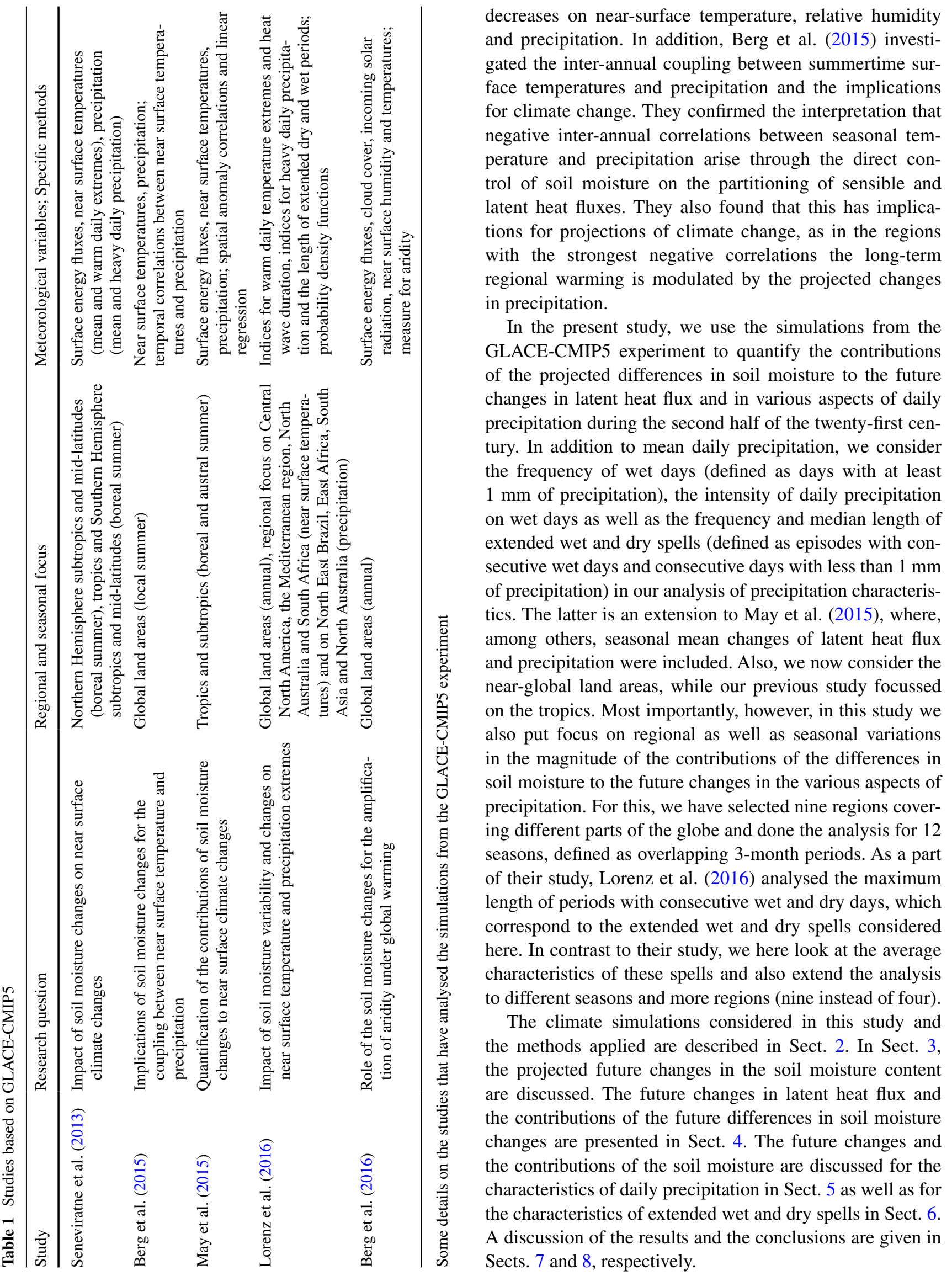




\section{Data and methodology}

\subsection{Climate simulations}

Five institutions contributed to the GLACE-CMIP5 experiment with their respective global climate models. These are the National Center for Atmospheric Research with the Community Earth System Model ("CESM"), Lund University with the EC-Earth coupled atmosphere-ocean model ("EC-EARTH") as well as the Geophysical Fluid Dynamics Laboratory ("GFDL"), the Institute Pierre Simon Laplace ("IPSL") and the Max-Planck-Institute ("MPI-ESM") with their respective ESM. For some relevant details on these models and references see Table 1 in May et al. (2015).

The GLACE-CMIP5 experiment includes three transient climate simulations for the period 1950 through 2100 . In these simulations the anthropogenic climate forcing agents are prescribed according to observations until 2005, and between 2006 and 2100 according to the Representative Concentration Pathway 8.5 scenario ("RCP8.5"; Moss et al. 2010; Riahi et al. 2011). For each climate model, these three simulations are two transient atmosphere/land only simulations ("ExpA" and "ExpB", respectively) and a reference simulation ("ExpR"). For CESM and MPI-ESM, ExpR corresponds to a standard CMIP5 simulation, while for EC-EARTH, GFDL and IPSL new reference simulations with the atmosphere/land only versions of these models were performed. This was necessary, since the physical parameterizations of these models had been updated after their standard CMIP5 simulations. In these new reference simulations, sea surface temperatures, sea ice, land use and atmospheric $\mathrm{CO}_{2}$ concentrations were prescribed from the respective CMIP5 simulation. Sea surface temperatures, sea ice, land use and atmospheric $\mathrm{CO}_{2}$ concentrations were prescribed according to ExpR in both ExpA and ExpB, but these two simulations differ in their prescribed soil moisture climatology. In ExpA, the seasonal cycle of the soil moisture content is constant, defined as the long-term mean for 1971-2000 obtained from ExpR. In ExpB the seasonal cycle of soil moisture varies in the course of the simulation, following the transient climatology from ExpR, using 30-year running means. The first and last 15 years of the simulation use the long-term means for 1950-1979 and 2056-2085, respectively.

We have chosen the two 30-year periods 1971-2000 and 2056-2085 representing climate conditions for the recent past and for the future for ExpA and $\operatorname{ExpB}$ (for soil moisture, latent heat flux and the different characteristics of daily precipitation) as well as for ExpR (for mean daily precipitation). We have chosen the period 2056-2085 instead of the last 30 years of the twenty-first century, which is often used, because after 2085 the soil moisture content prescribed in ExpB does not vary from year to year, which suppresses the inter-annual variability of soil moisture in this experiment.

\subsection{Methodology}

We present near-global maps for the boreal and the austral summer seasons, covering June through August ("JJA") and December through February ("DJF"), respectively. However, all analyses have been performed for 12 seasons, defined as overlapping 3-month periods ranging from January through March ("JFM"), over February to April ("FMA"), etc., to DJF, covering the entire calendar year. Results for these 12 seasons and, hence, the variability of the results in the course of the year are presented for selected regions. We have evaluated 26 regions following the definition in Seneviratne et al. (2012) except for northeastern Canada and Greenland, where we use $80^{\circ} \mathrm{N}$ as the northern boundary of the region instead of $85^{\circ} \mathrm{N}$. These regions cover all continents except Antarctica (Fig. 1). Here, we show results for nine of these regions from several continents and both hemispheres, excluding regions reaching high northern latitudes. The latter is due to the fact that these regions are covered with snow during the cold season, so that the impact of the soil moisture is suppressed during that time of the year. The selected regions are Central North America ("CNA"), Central Europe ("CEU"), the Mediterranean region ("MED"), Central Asia ("CAS"), South Asia ("SAS"), Western Africa ("WAF"), Amazonia ("AMZ"), Southern Africa ("SAF") and Northern Australia ("NAU"). See Fig. 1 for the location and the extent of these regions.

To assess the degree of similarity between the future changes in the soil moisture content and the corresponding changes in daily mean precipitation, we have computed anomaly correlation coefficients ("ACC") between the percent differences in soil moisture between ExpB and ExpA for 2056-2085 and the mean daily precipitation changes

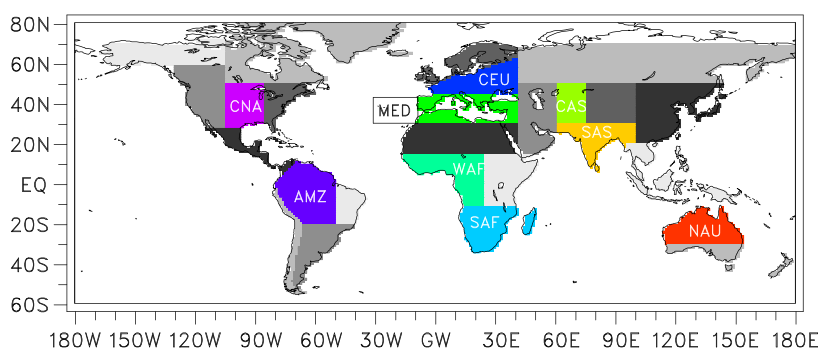

Fig. 1 The nine regions presented here in different colours. These are Central North America ("CNA"), Central Europe ("CEU"), the Mediterranean region ("MED"), Central Asia ("CAS"), South Asia ("SAS"), Western Africa ("WAF"), Amazonia ("AMZ"), Southern Africa ("SAF"), and Northern Australia ("NAU"). Marked in different shades of grey are the remaining 17 regions that have been analysed as well but are not presented here. See Sect. 2.2 for details 
between 2056-2085 and 1971-2000 for ExpR. This was done for each of the five climate models, the 12 seasons and the 26 regions. Only grid points, where the respective differences are significant at the $95 \%$ level according to a two-sided Student's $t$ test, enter the computations. In addition, we have evaluated the representativeness of the coefficients by comparing them against the sampling error. For the latter, we have applied a nonparametric bootstrapping procedure, where 200 samples have been generated from the grid point data for a specific region (as well as for a particular climate model and season). The ACCs have been computed for these samples, and the difference between the 75th and the 25th percentile of the resulting collection of ACCs is used as a measure of the sampling error. We regard a coefficient to be representative for the region in question, if the ratio between the absolute value of the ACC and the measure of the sampling error (which is positive by definition) exceeds a value of 2.5. This threshold has been chosen, because the number of cases with non-representative coefficients strongly varies for values up to 2 but increases only slightly for values exceeding 2 .

To quantify the contributions of the projected differences in soil moisture to the future changes in a particular meteorological variable, we have performed a linear regressions analysis between the future changes (the difference between 2056-2085 and 1971-2000 for ExpB) and the contributions of the prescribed soil moisture changes to these differences (the difference between ExpB and ExpA for 2056-2085) for the variable in question. This was done for each of the five climate models, the 12 seasons and the 26 regions, and the representativeness of the values of the slope of the linear regression line ("SLR") for a specific region has been determined by the nonparametric bootstrap method that has also been applied to the ACCs. The respective coefficients of determination, which indicate how well the actual data fit the linear regression line, are not considered here, but generally these coefficients follow the magnitude of the ratios, which define their representativeness. An SLR of 1 means that (to the extent the linear regression model actually fits the data) the entire future change is associated with the projected soil moisture differences. A value exceeding 1 illustrates that only a fraction of the future change is related to soil moisture, while a value between 0 and 1 indicates that other processes offset the change associated with soil moisture. Finally, a negative value means that the future change and the effect of soil moisture tend to have opposite signs. Similar to the anomaly correlation coefficients, only grid points, where the respective differences are significant at a certain level, enter the computations. As for the latent heat flux, both differences are significant at the $95 \%$ level based on a two-sided Student's $t$ test. For the characteristics of daily precipitation, on the other hand, a grid point is considered when either the future change is significant at the $95 \%$ level or the contribution of the soil moisture difference is significant at the $90 \%$ level. The contrasting significant levels for the two kinds of differences account for the fact that, unlike latent heat flux (see Sect. 4), for the characteristics of daily precipitation the contributions of the soil moisture are markedly weaker than the corresponding future changes (see Sect. 5). For the characteristics of daily precipitation, grid points are considered in cases where at least one of the differences is significant (for the seasonal means both differences need to be significant). By this we deal with the fact that the statistics based on the daily values are stronger affected by sub-seasonal variations than the seasonal means and, hence, more variable. This results in generally lower significance levels for the characteristics of daily precipitation. The significance of the grid point data has been obtained by means of a nonparametric bootstrapping procedure, where 200 samples have been generated for the time series of daily precipitation for each of the 30-year periods used to infer the differences between the respective simulations or periods. The differences have been computed for all the samples, and the overlap between the corresponding probability distributions is used as a measure of the significance level.

Both methods have already been employed in May (2015) to quantify the contributions of the projected soil moisture differences to the future climate changes in the tropics. Seneviratne et al. (2013), on the other hand, applied linear regression analysis to quantify the impact of the differences in latent heat flux associated with the projected soil moisture changes on the future changes in nearsurface temperatures (both the mean and warm extremes) in the Mediterranean region. Lorenz et al. (2016) compared spatially aggregated probability density functions for the different simulations and periods with each other to assess the impact of soil moisture variability and trends on future changes in temperature and precipitation extremes in selected regions.

\section{Soil moisture content}

Figure $2 \mathrm{a}, \mathrm{b}$ show the percent differences of the prescribed soil moisture content between ExpB and ExpA for 20562085 with respect to ExpA for 1971-2000, averaged over the five climate models for JJA and DJF, respectively. The geographical distributions reveal a general tendency of increased soil moisture in the tropics and at high latitudes in the Northern Hemisphere and decreased soil moisture in the subtropics, in the southern parts of North America and Europe as well as in Central Asia in both seasons. In the tropics the increases are particularly strong in eastern Brazil, Eastern Africa and South Asia. In the tropics as well as in the Southern Hemisphere extratropics, the signs of the 


\section{Soil moisture content}

(a) ExpB-ExpA / fut / JJA

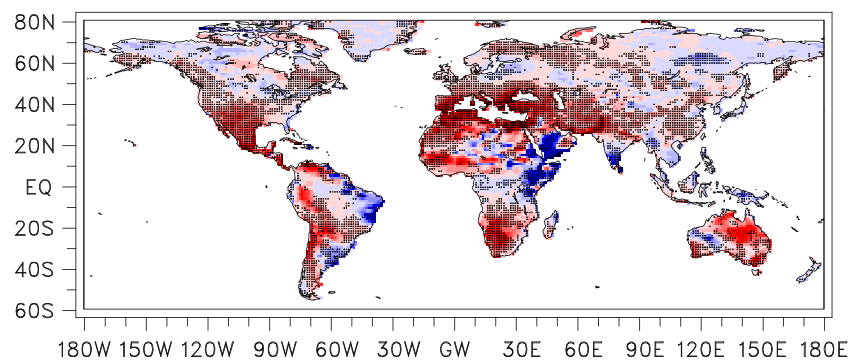

(b) ExpB-ExpA / fut / DJF

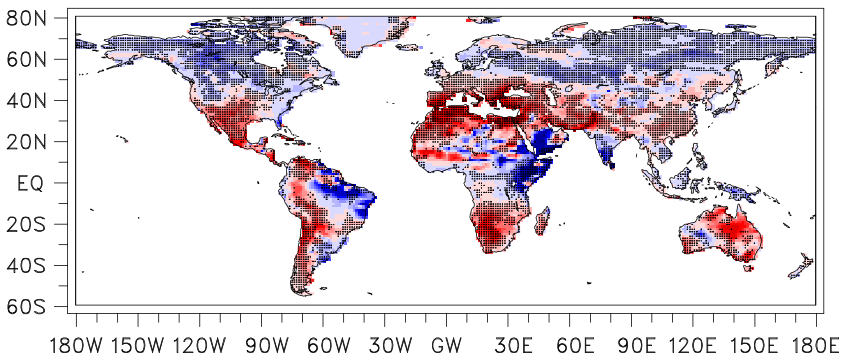

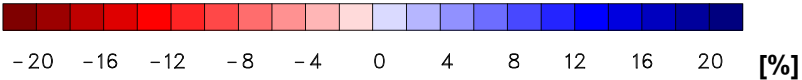

Mean daily precipitation

(c) ExpR / fut-pre / JJA

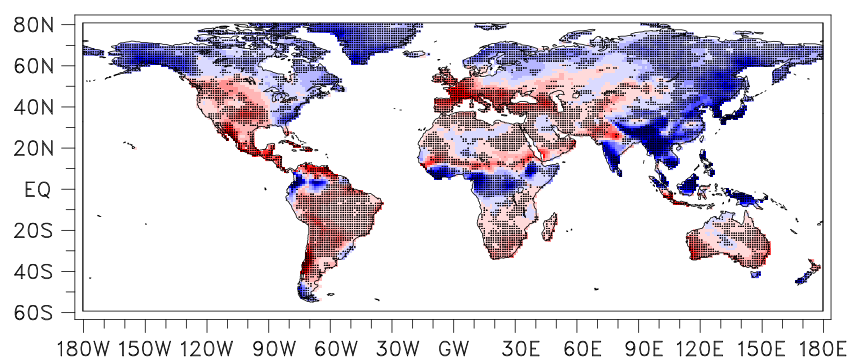

(d) $\operatorname{ExpR} /$ fut-pre / DJF

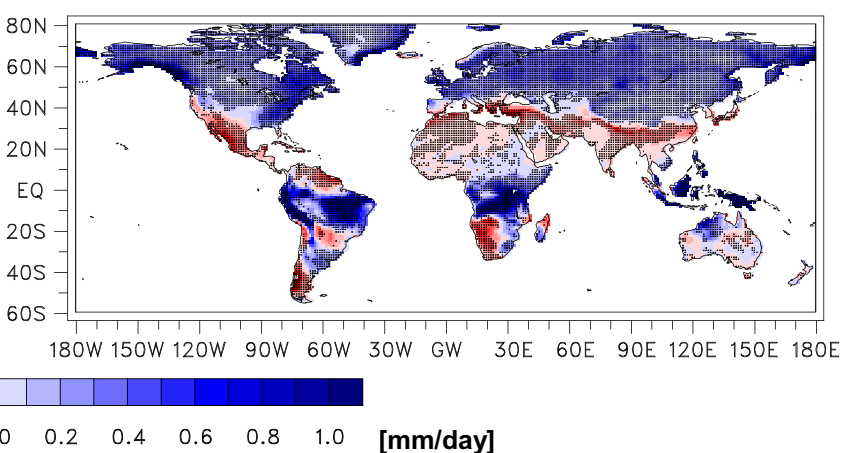

Fig. 2 Percent differences in seasonal mean moisture content between ExpB and ExpA for 2056-2085 relative to ExpA for 20562085 in (a) boreal summer (JJA; June through August) and b austral summer (DJF; December through February), averaged over the five climate models. Also the differences in the seasonal mean daily pre-

projected changes in soil moisture vary only little between the two seasons. In the Northern Hemisphere extratropics some marked differences between the two seasons occur. In Europe, the area with reduced soil moisture extends further north into Central and Northern Europe in JJA (Fig. 2a), while in DJF the decrease in the soil moisture content is mostly restricted to southern Europe (Fig. 2b). Similar tendencies are found for North America and Central Asia.

By this the future soil moisture changes follow by and large the corresponding changes in mean daily precipitation with a tendency of increasing (decreasing) soil moisture in regions with increases (decreases) in precipitation (Fig. 2c, d). We find an overall tendency of increased precipitation in the tropics and at high northern latitudes and decreased precipitation in the subtropics in both seasons. In the Northern Hemisphere extratropics the changes in mean precipitation vary considerably between the two seasons. In DJF, precipitation is significantly increased over the entire Northern Hemisphere mid- and high latitudes (Fig. 2c), while cipitation between 2056-2085 and 1971-2000 for ExpR in c JJA and d DJF, averaged over the five climate models. The black dots mark areas, where at least four of the five models agree on the sign of the differences. Units are $\%(\mathbf{a}, \mathbf{b})$ and $\mathrm{mm} /$ day $(\mathbf{c}, \mathbf{d})$; the contour intervals are $2 \%$ and $0.1 \mathrm{~mm} /$ day $(\mathbf{c}, \mathbf{d})$, respectively

in JJA precipitation is decreased in the western part of the United States as well as in western and southern Europe (Fig. 2d). Despite the notable increases of precipitation in the entire tropics (except for Amazonia in JJA), soil moisture increases only slightly in the central tropics (Fig. 2a, b), as the soil moisture is saturated or almost saturated in this region under present-day climate conditions.

The general tendency of increasing (decreasing) soil moisture in areas with future increases (decreases) in mean precipitation is also reflected in the predominantly positive ensemble mean values of the ACC between the soil moisture changes and the differences in mean daily precipitation for the nine selected regions (Fig. 3; see Sect. 2.2 for details). In addition to this overall tendency, the ensemble mean values of the correlation coefficients display regional and seasonal variations and cover differences between the individual models.

All regions except the Mediterranean region (Fig. 3c) and to some extent Central Asia (Fig. 3d), show a distinct 
Soil moisture content (ExpB-ExpA / fut) vs. precipitation (ExpR / fut-pre)

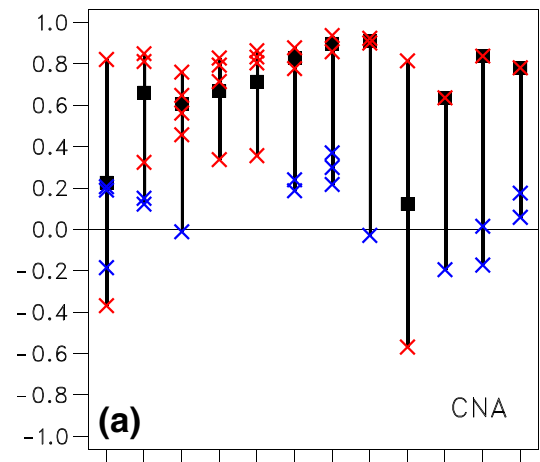

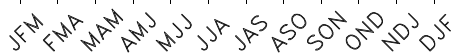

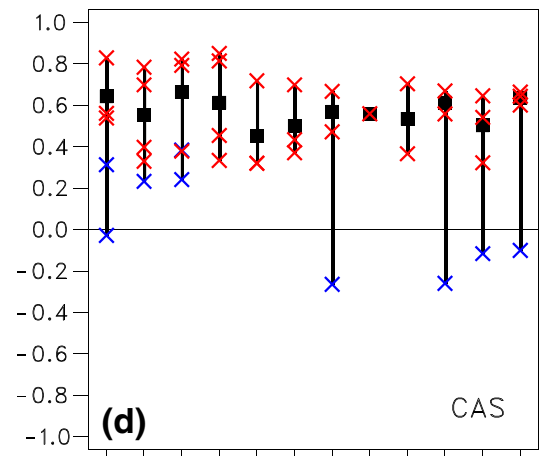

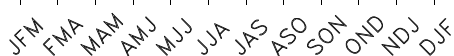

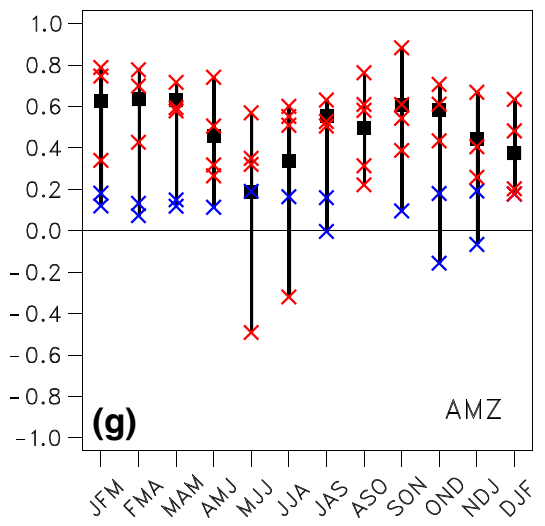

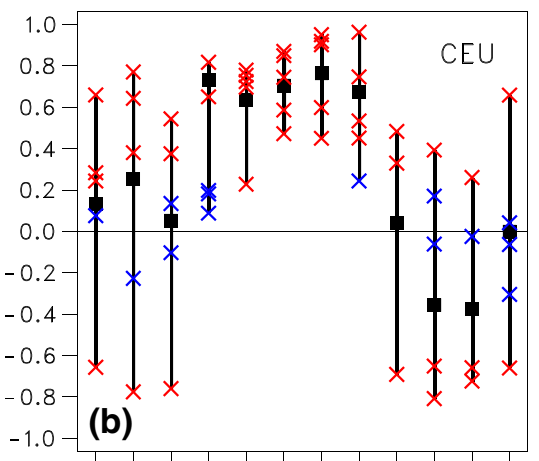

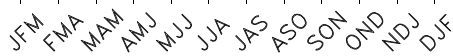

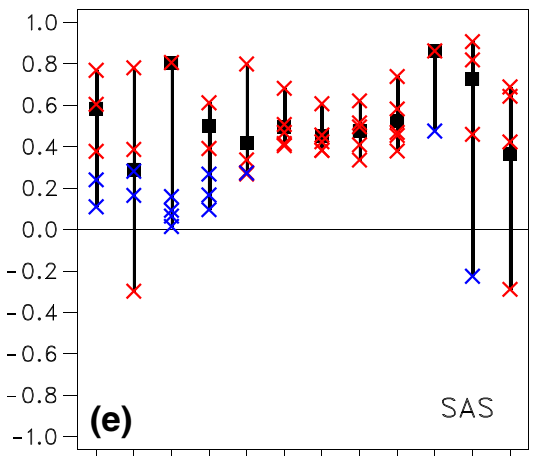

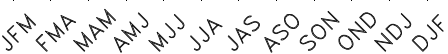

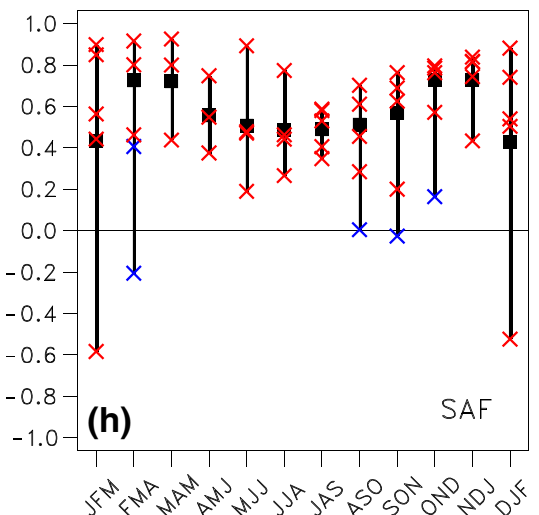

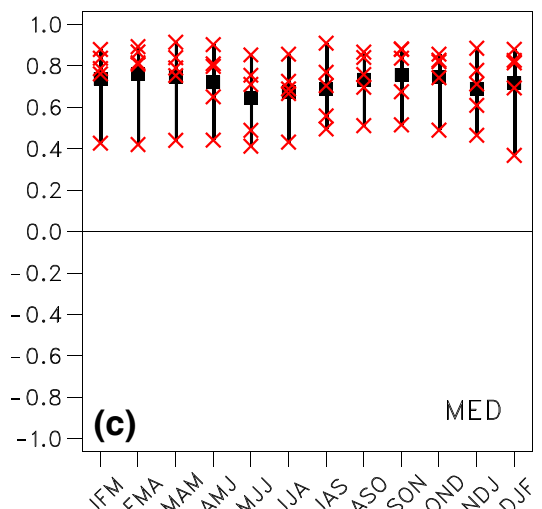
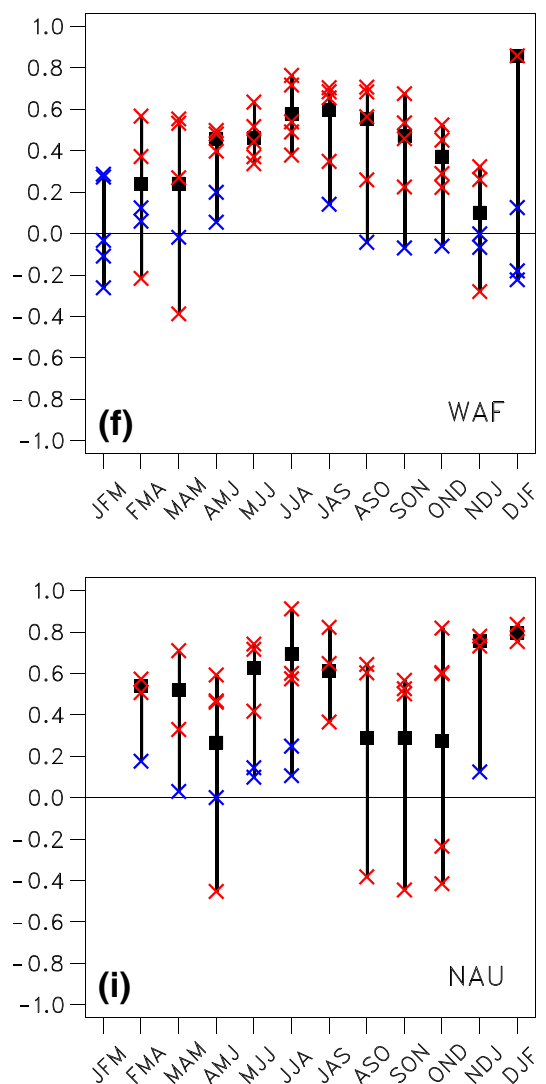

Fig. 3 Anomaly correlation coefficients between the percent differences in seasonal mean moisture content between ExpB and ExpA for 2056-2085 relative to ExpA for 2056-2085 and the differences in seasonal mean daily precipitation between 2056-2085 and 19712000 for ExpR for 12 seasons and nine regions (see Sect. 2.2 for details). Only grid points where both differences are significant at the $95 \%$ level are considered. Also, only values for areas with at least 40 such grid points for an individual climate model are included. The

seasonal cycle of the ACCs, with one or two periods with relatively large values and one or two periods with rather small coefficients. Several regions, namely, Central North America (Fig. 3a), Central Europe (Fig. 3b) and Western Africa (Fig. 3f), are characterized by a unimodal seasonal boxes mark the averages over the models with representative values (see Sect. 2.2 for details). The vertical lines indicate the range of the values for all individual models. The crosses illustrate the anomaly correlation coefficients for the individual models, representative (nonrepresentative) values by the red (blue) ones. Units are standard unit. Note that for Northern Australia none of the climate models has a sufficient number of grid points in JFM

cycle with large positive values in boreal summer and either small positive values or negative values for Central Europe in boreal winter. In Western Africa the correspondence between precipitation and soil moisture changes is relatively strong during boreal summer with large fractions 
of annual precipitation associated with the West African monsoon. The other regions are characterized by a bimodal shape with rather small values of the ACC in different seasons. In Amazonia (Fig. 3g), relatively small correlation coefficients are found in early boreal summer and early austral summer (the periods with large fractions of annual precipitation in the parts of Amazonia that are located north and south of the equator, respectively). This is related to projected precipitation increases during these parts of the year (not shown here) and decreasing soil moisture throughout the year in this region for all but one of the climate models. In Northern Australia (Fig. 3i) and to some extent in Southern Africa (Fig. 3h), relatively large ACCs are found in both austral winter and austral summer and small ones during the transition seasons. That the correlation coefficients hardly vary in the course of the year in the Mediterranean region and Central Asia, illustrates a very good correspondence between precipitation changes and the soil moisture content in these two regions. In the Mediterranean region this is due to the fact that all five climate models project decreases in precipitation in all seasons (not shown here), resulting in decreasing soil moisture in all seasons and, hence, the good correspondence. Three of the five models show the same behaviour in Central Asia, while the two other models project increases in precipitation during the cold season, accompanied by increases or weak decreases of soil moisture during this part of the year.

The values of the ACC and, hence, the correspondence between the future changes in precipitation and soil moisture vary considerably between the individual climate models (indicated by the vertical bars in Fig. 3). In the majority of regions and seasons, the correlation coefficients are positive for all five models and only occasionally an individual model is characterized by a negative value. However, in Central Europe (Fig. 3b) and to some extent Western Africa (Fig. 3f) a majority of the models are characterized by negative ACCs during part of the year. The negative correlation coefficients in Central Europe during boreal winter are caused by decreases in soil moisture (persisting from summer with decreasing precipitation) despite increasing precipitation in a large fraction of this region. In a few regions the width of the ranges covering the individual climate models varies in the course of the year. In Central Europe (Fig. 3b), for instance, the ranges are wider in the cold than during the warm season, while in South Asia (Fig. 3e) the ranges are very narrow during the monsoon season and particularly wide in boreal winter. In Southern Africa (Fig. 3h), on the other hand, rather wide ranges are found in austral summer, when a large fraction of the annual rainfall occurs. In Amazonia (Fig. 3g) and Northern Australia (Fig. 3i) the spread between then individual models is particularly large during the transition seasons.

\section{Latent heat flux}

To a first order, soil moisture affects the turbulent fluxes of sensible and of latent heat at the land surface, and to a second order, near-surface temperature and precipitation (e.g., Seneviratne et al. 2010). In addition, local meteorological factors, such as cloudiness (controlling the amount of incoming solar radiation) and the stability of the atmospheric boundary layer, as well as induced circulation changes, which affect the turbulent energy fluxes and, hence, the soil moisture-climate coupling, play a role.

Figure $4 \mathrm{a}, \mathrm{b}$ show the differences in seasonal mean latent heat flux between 2056-2085 and 1971-2000 for ExpB, namely, the future changes in latent heat flux in response to the future anthropogenic forcing, averaged over the five climate models for JJA and DJF, respectively. There is a general tendency of increased latent heat fluxes in the tropics and at the mid- and high latitudes in the Northern Hemisphere and decreased latent heat fluxes in the subtropics in both seasons. Notable differences between the two seasons are the reduced latent heat fluxes in Central America and the southern part of North America, in southern Europe and in the central part of South America in JJA (Fig. 4a), compared to increases in these regions in DJF (Fig. 4b). Furthermore, the projected changes are generally strongest in the respective summer hemisphere, i.e., north of the equator in JJA and south of the equator in DJF.

Figure $4 \mathrm{c}, \mathrm{d}$ show the differences in seasonal mean latent heat flux between ExpB and ExpA for 2056-2085, that are, the contributions of the projected differences in soil moisture to the future changes in latent heat flux, averaged over the five climate models. The geographical distributions reveal considerable contributions to the future changes in latent heat flux, in particular in areas with decreases in the latent heat flux, i.e., the subtropics in both seasons (Fig. 4c, d) as well as the southern part of North America, the western Unites States, southern Europe and large parts of Central Asia in JJA (Fig. 4c). In these regions the magnitudes of the decreases actually exceed the corresponding future (predominantly negative) changes in latent heat flux, indicating that other processes offset to some extent the marked decreases associated with the soil moisture differences. In regions with projected increases in latent heat fluxes, on the other hand, the soil moisture changes give small, but generally positive, contributions (Fig. 4c, d). This is especially the case in the mid- and high latitudes of the Northern Hemisphere, where other processes lead to pronounced future increases. The geographical distributions of the contributions of the soil moisture differences to the changes in latent heat flux are broadly similar to corresponding distributions of the soil moisture changes (see Fig. 2a, b), supporting the notion that negative (positive) soil moisture 


\section{Latent heat flux}

(a) ExpB / fut-pre / JJA

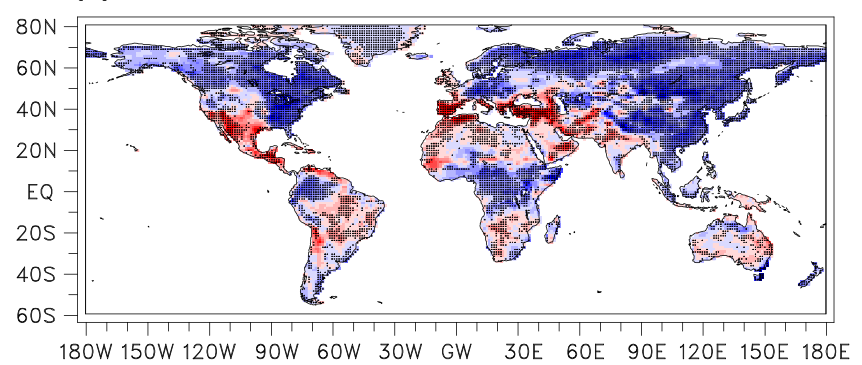

(c) ExpB-ExpA / fut / JJA

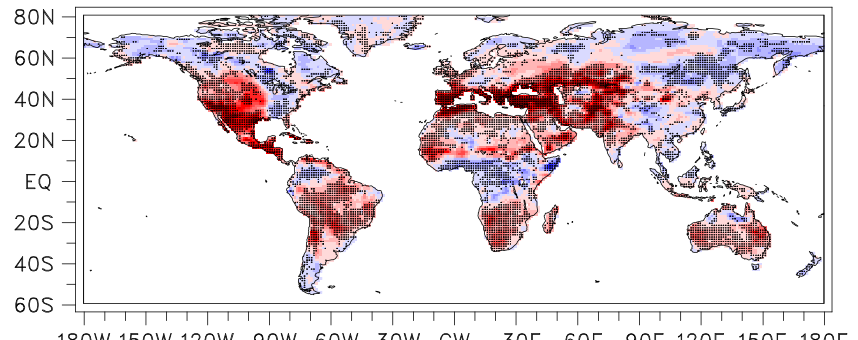

180W 150W 120W 90W 6OW 30W GW 30E 60E 90E 120E $150 \mathrm{E}$ 180E (b) ExpB / fut-pre / DJF

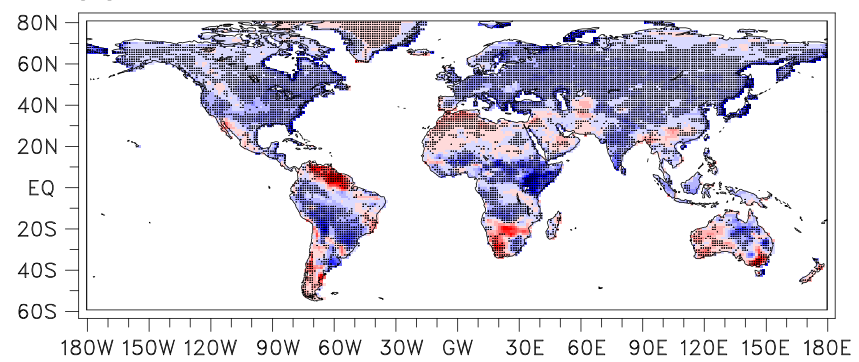

(d) ExpB-ExpA / fut / DJF

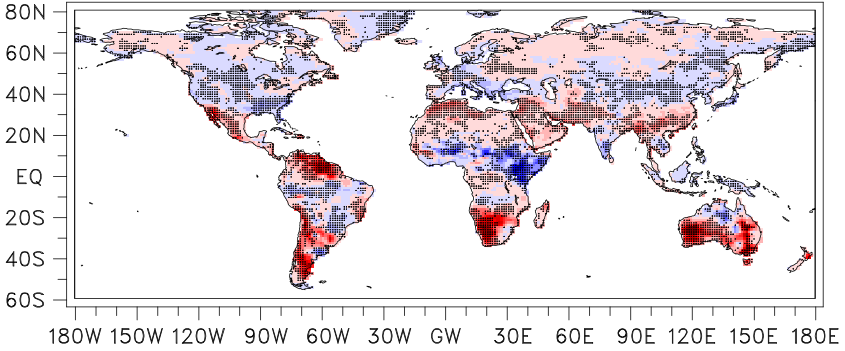

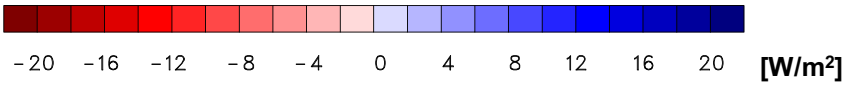

Fig. 4 Differences in seasonal mean latent heat flux between 20562085 and 1971-2000 for ExpB in (a) boreal summer (JJA) and $\mathbf{b}$ austral summer (DJF), averaged over the five climate models. Also the differences between ExpB and ExpA for 2056-2085 in c JJA and d
DJF, averaged over the five climate models. The black dots indicate, where at least four of the five models agree on the sign of the differences. Units are $\mathrm{W} / \mathrm{m}^{2}$; the contour interval is $2 \mathrm{~W} / \mathrm{m}^{2}$

of the year with the smallest values in the beginning and the largest ones in the end of the year. Pronounced seasonal variations are found in Central North America, Central Europe and, especially, Central Asia. In both Central North America (Fig. 5a) and Central Europe (Fig. 5b), the contributions of the soil moisture changes are rather strong (about 0.8 to 1 ) in boreal spring and weak (roughly 0.5) in autumn and early winter. In Central Asia (Fig. 5d), on the other hand, the values of the SLR are rather small in the warm period from late spring to early boreal autumn but relatively large in winter. In the Mediterranean region (Fig. 5c) and Northern Australia (Fig. 5i) the contributions of the soil moisture changes are also relatively weak in local summer (about 0.7 for the Mediterranean region and 0.6 for Northern Australia) and strong in local autumn (about 0.9 and 0.7 , respectively). The relatively small ensemble mean values of the SLR indicate that in the respective regions and seasons the changes in the latent heat flux associated with the soil moisture differences are typically offset by other processes. As seen in the geographical distributions for JJA and DJF (see Fig. 4), this is often the case in areas where the soil moisture changes lead to marked reductions of the latent heat fluxes, such as, the subtropics in both seasons and the southern parts Asia. In the latter region the slopes increase in the course 
Latent heat flux - ExpB / fut-pre vs. ExpB-ExpA / fut

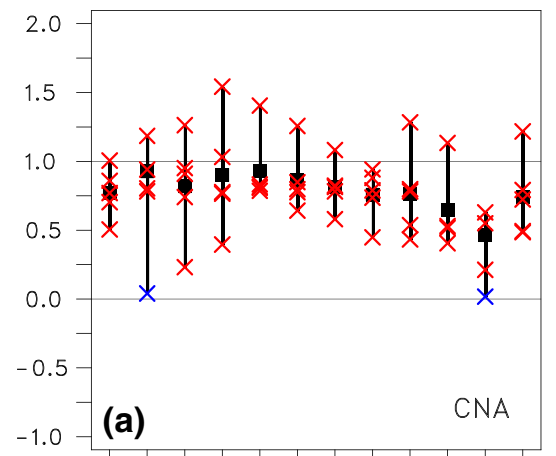

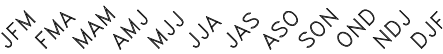

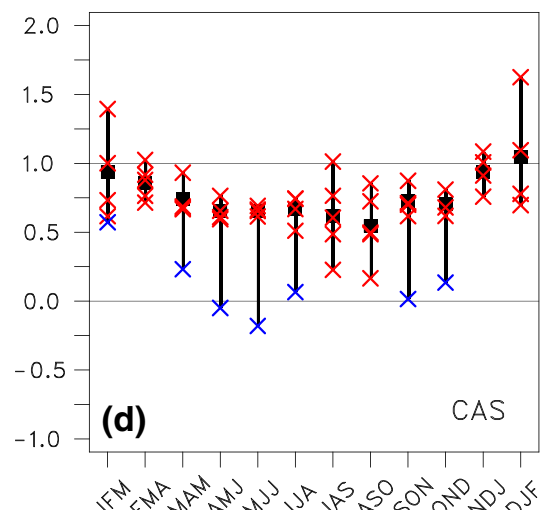

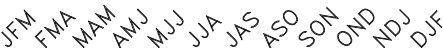

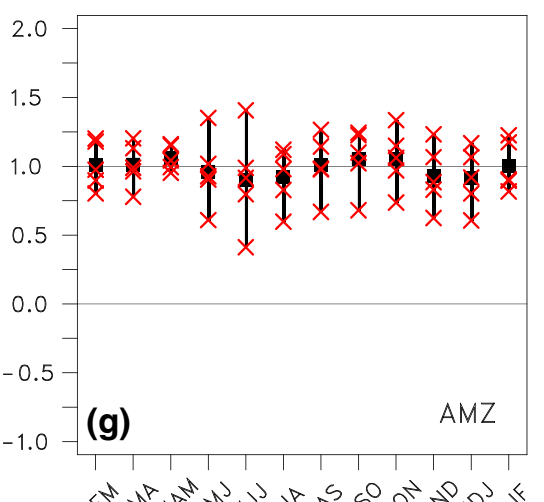

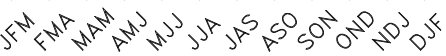
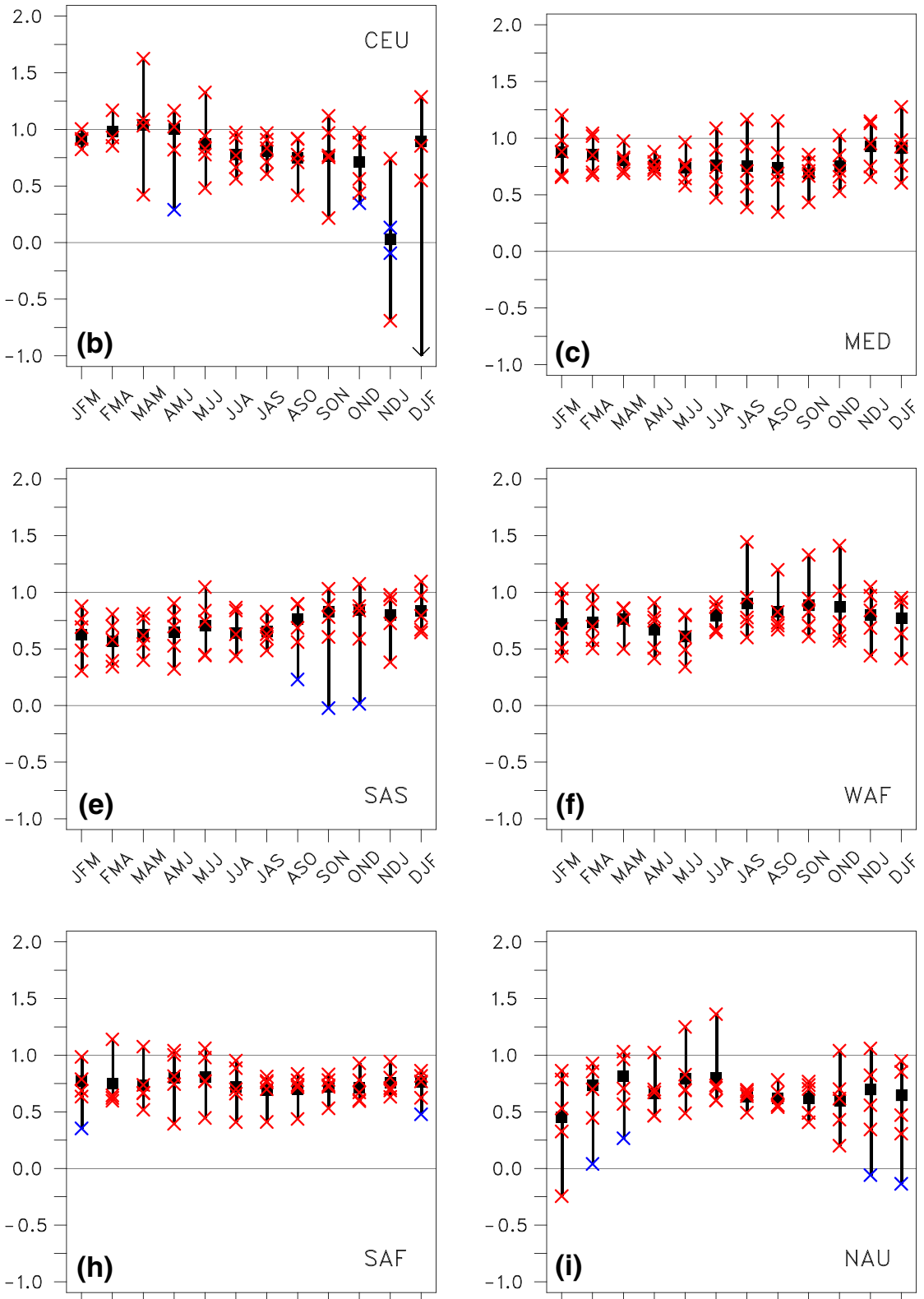

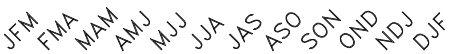

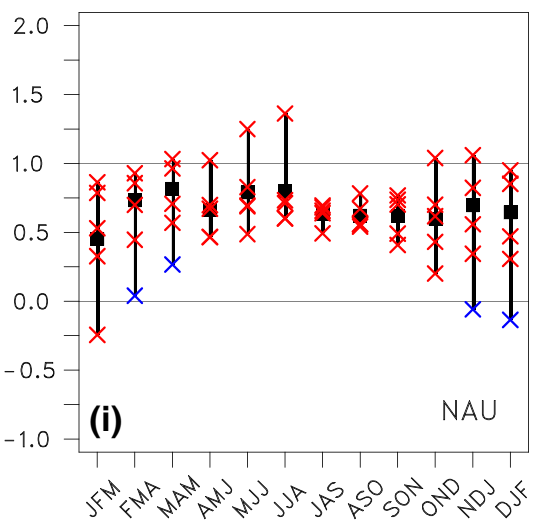

Fig. 5 Slopes of the linear regression line between the differences in seasonal mean latent heat flux between 2056-2085 and 19712000 for ExpB and the differences in seasonal mean latent heat flux between ExpB and ExpA for 2056-2085 for 12 seasons and nine regions. Only grid points where both differences are significant at the 95\% level are considered. Also, only values for areas with at least 40 such grid points for an individual climate model are included. The

of North America and Europe as well as Central Asia in JJA.

Despite the marked differences between the individual climate models, there are very few regions and seasons, where the SLRs for a single model are slightly negative, but in only two cases the values are found to be representative. boxes mark the averages over the models with representative values. The vertical lines illustrate the range of the values for all individual models, with arrow heads at the end of the lines pointing at values exceeding the plotting range. The crosses indicate the slopes for the individual models, representative (non-representative) values by the red (blue) ones. Units are standard unit

This means that all models confirm the general tendency that the future changes in latent heat flux have the same signs as the contributions of the soil moisture changes. There are, on the other hand, several cases, where one or several models give SLRs exceeding a value of 1, meaning that other processes amplify the changes in latent heat flux 
caused by the differences in soil moisture. The slopes of the linear regression line for the different climate models vary both by region and by season, that is, in some cases the individual models agree quite well on the extent to which soil moisture contributes to the future changes in latent heat fluxes but diverge in other situations. Regions, where the models agree quite well throughout the year, are the Mediterranean region (Fig. 5c), Amazonia (Fig. 5g) and Southern Africa (Fig. 5h). Relatively strong variations between the individual models are found in South Asia (Fig. 5e) and Western Africa (Fig. 5f) at the end of the respective monsoon season. In Western Africa the contribution of the soil moisture changes is amplified by one particular model, but in South Asia the contribution is entirely offset by other processes. In Northern Australia (Fig. 5i) the different models agree very well in late austral winter but vary markedly during the rest of the year, while in Central North America (Fig. 5a) as well as in Central Europe (Fig. 5b) the models differ most during the transition seasons.

\section{Characteristics of daily precipitation}

In this section we present the future changes in various characteristics of daily precipitation in response to the future anthropogenic forcing and assess the contributions of the differences in soil moisture to these changes. In addition to seasonal mean daily precipitation (the amount of daily precipitation averaged over the season), the frequency of wet days (defined as days with at least $1 \mathrm{~mm}$ of precipitation) and the intensity of daily precipitation (the amount of daily precipitation averaged over all wet days) are considered. In order to avoid that a few wet days dominate the statistics, we have only analysed grid points with at least 30 wet days in a specific season during the 30 -year period of simulation (corresponding to a bit more than $1 \%$ of all days) for each climate model. In boreal winter, for instance, it is the Sahara desert in northern Africa, which typically has not enough wet days, and in austral winter it is the case for a part of eastern Brazil and the centre of Southern Africa. In the geographical distributions to be presented in the following, these regions (more precisely, the regions where none of the five individual models has sufficient wet days) are marked in grey.

As mentioned in Sect. 3, the anthropogenic climate forcing leads to increases in mean daily precipitation in the tropics and at high northern latitudes and decreases in the subtropics in both JJA and DJF (Fig. 6a, b). Distinct differences between the two seasons are found in the Northern Hemisphere extratropics with increases in the mid- and high latitudes in DJF (Fig. 6b) and decreases in the western part of the Unites States as well as in western and southern Europe in JJA (Fig. 6a).
The changes in mean daily precipitation merge the future changes in the intensity of daily precipitation (Fig. 6c, d) and the future changes in the frequency of wet days (Fig. 6e, f). The intensity of daily precipitation is generally increased over most of the global land area. This is particularly the case in DJF, while in JJA the intensity of daily precipitation is slightly reduced in some parts of the subtropics as well as in the southern part of North America and in south-western Europe (Fig. 6c). The changes in the frequency of wet days, however, vary considerably between the two seasons. In DJF the frequency of wet days is increased in the tropics, particularly in Africa, and in the Northern Hemisphere extratropics and decreased elsewhere (Fig. 6f). In JJA the frequency of wet days is increased in several confined areas, i.e., Amazonia, parts of tropical Africa and a part of Central Asia, and decreased elsewhere (Fig. 6e). Therefore, in DJF the regions with the most pronounced increases in mean daily precipitation stand out as those, where both the intensity of daily precipitation and the frequency of wet days are significantly increased, namely, in the Northern Hemisphere mid- and high latitudes and tropical Africa (Fig. 6b). In JJA, on the other hand, both the intensity of daily precipitation and the frequency are only increased in Amazonia and tropical Africa and decreased in the southern part of North America and in south-western Europe, leading to marked increases of mean daily precipitation in Amazonia and tropical Africa and decreases in the southern part of North America and in south-western Europe (Fig. 6a).

Most of the five individual models agree on the signs of the projected changes in both the frequency of wet days and the intensity of daily precipitation over most of the global land area (Fig. 6c-f). The future regional changes in mean daily precipitation, on the other hand, are less consistent between the individual models (Fig. 6a, b), which is accounted for by the fact that future changes in the frequency of wet days and in the intensity often have opposite signs in those areas, where the frequency of wet days is reduced. This indicates that regional variations in the projected changes in mean daily precipitation between individual climate models might be largely due to the specific balance between the future changes in the frequency of wet days and in the intensity of daily precipitation.

In JJA, the projected changes in soil moisture lead to decreases in mean daily precipitation over much of the global land area, particularly in the western part of North America, southern Europe and Central Asia as well as in the southern part of South America and much of Africa (Fig. 7a). As for the impact of the differences in soil moisture, the changes in the intensity of daily precipitation (Fig. 7c) and in the frequency of wet days (Fig. 7e) are largely consistent, that is, notable increases (decreases) in the intensity of daily precipitation tend to occur in areas 
(a) ExpB / fut-pre / JJA

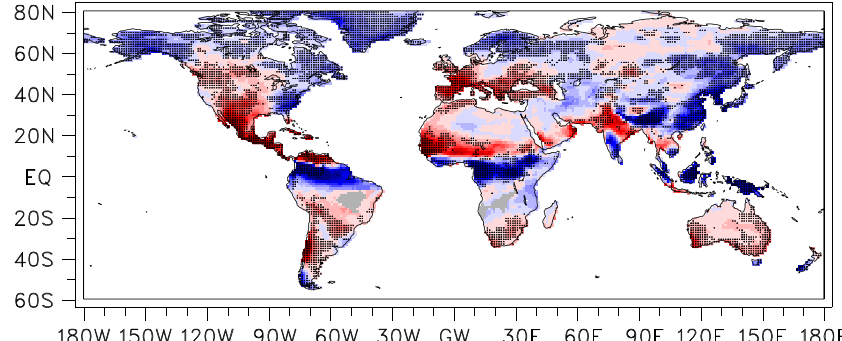

Mean daily precipitation

(b) ExpB / fut-pre / DJF

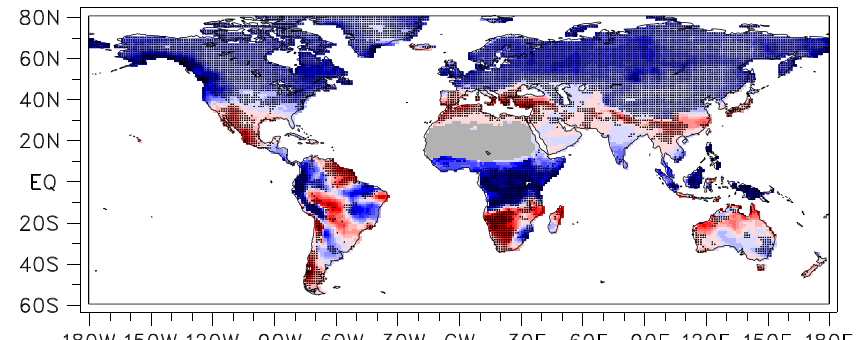

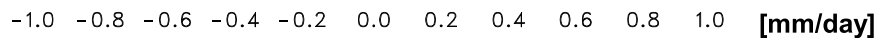

Intensity of daily precipitation

(c) ExpB / fut-pre / JJA

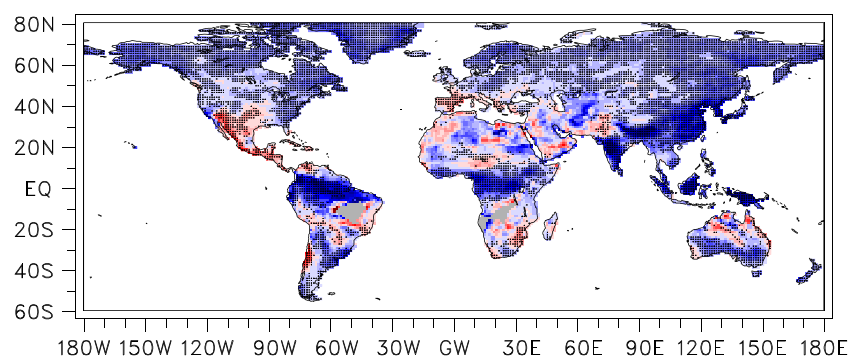

(d) ExpB / fut-pre / DJF

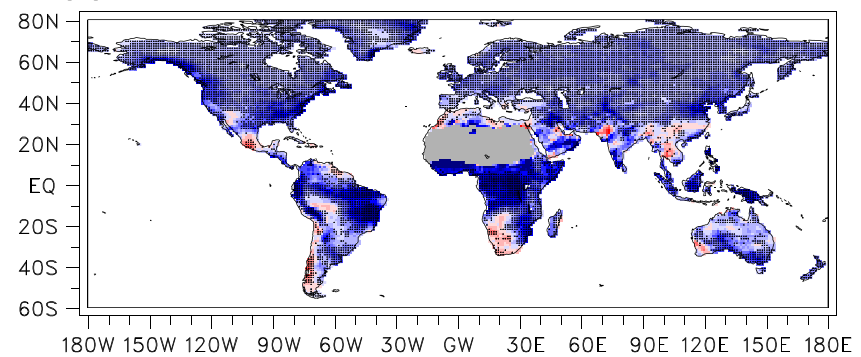

\begin{tabular}{l|lll|l|l|l|l|l|l|lllll}
\hline & & & & & & & & & & & & & \\
\\
-2.0 & -1.6 & -1.2 & -0.8 & -0.4 & 0.0 & 0.4 & 0.8 & 1.2 & 1.6 & 2.0 & [mm/day]
\end{tabular}

Frequency of wet days

(e) ExpB / fut-pre / JJA

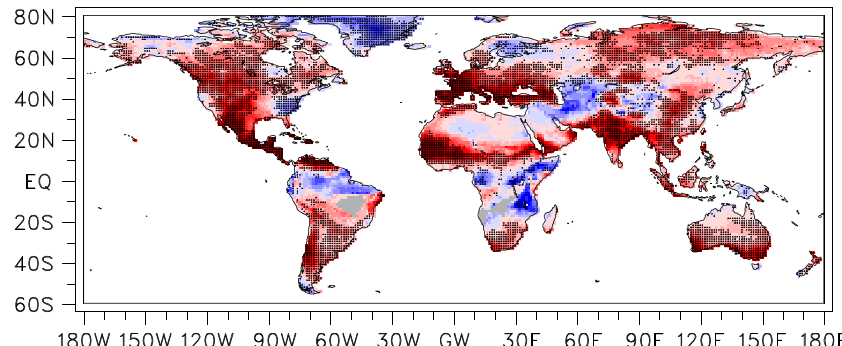

(f) ExpB / fut-pre / DJF

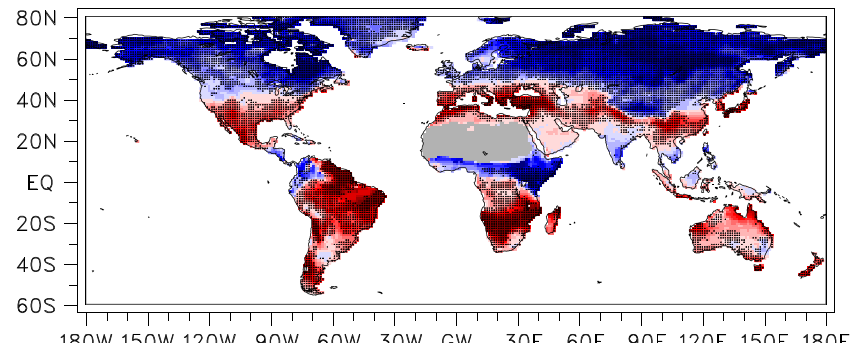

180W 150W 120W 9OW 6OW 3OW GW 30E 6OE 9OE $120 \mathrm{E}$ 150E $180 \mathrm{E}$

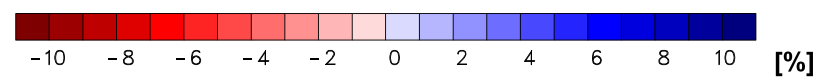

Fig. 6 Differences in seasonal mean daily precipitation (upper row), the intensity of daily precipitation on wet days (middle row) and the frequency of wet days (lower row) between 2056-2085 and 19712000 for $\operatorname{ExpB}$ in $(\mathbf{a}, \mathbf{c}, \mathbf{e})$ boreal summer (JJA) and (b, d, f) austral summer (DJF), averaged over the five climate models. Grid points, where none of the five individual models has at least 30 wet days in either period during the respective season, are left in grey. The black dots indicate, where at least four of the five models agree on the sign of the differences. Units are $\mathrm{mm} / \mathrm{day}(\mathbf{a}-\mathbf{d})$ and $\%(\mathbf{e}, \mathbf{f})$; the contour intervals are $0.1 \mathrm{~mm} /$ day $(\mathbf{a}, \mathbf{b}), 0.2 \mathrm{~mm} /$ day (c, d) and $1 \%(\mathbf{e}, \mathbf{f})$, respectively

southern Europe and Central Asia as well as in the southern part of South America and much of Africa. Also in DJF, the changes associated with the differences in soil moisture are consistent between the intensity of daily precipitation 
(a) ExpB-ExpA / fut / JJA

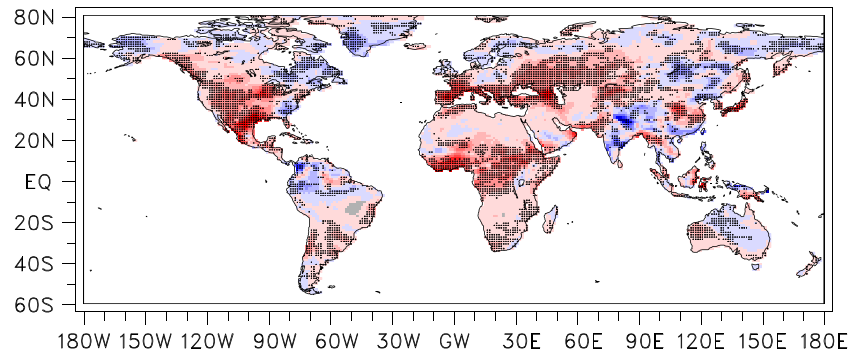

Mean daily precipitation

(b) ExpB-ExpA / fut / DJF

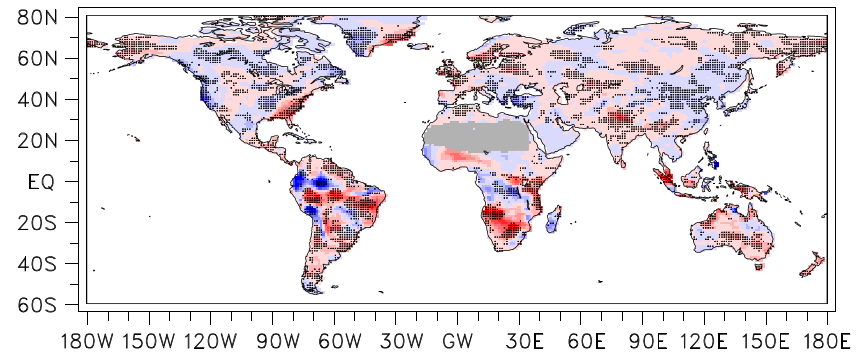

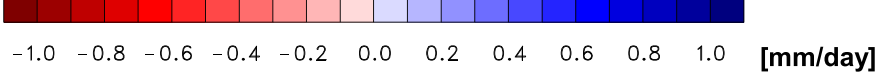

(c) ExpB-ExpA / fut / JJA

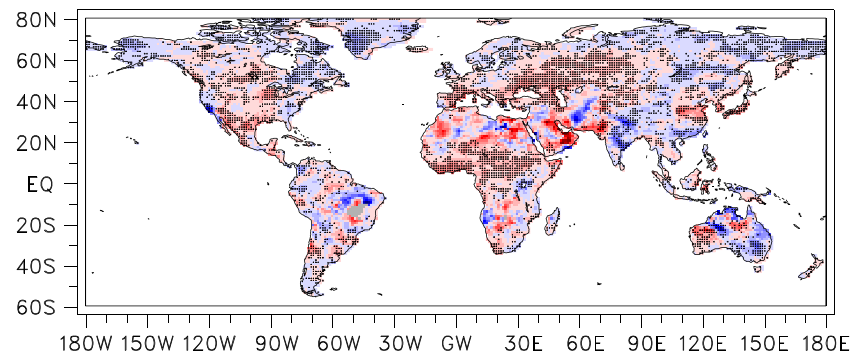

Intensity of daily precipitation

(d) ExpB-ExpA / fut / DJF

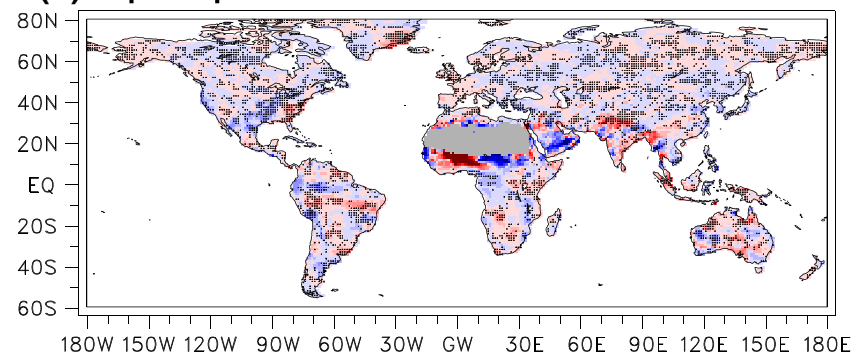

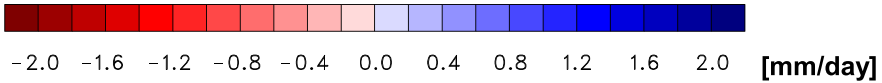

Frequency of wet days

(e) ExpB-ExpA / fut / JJA

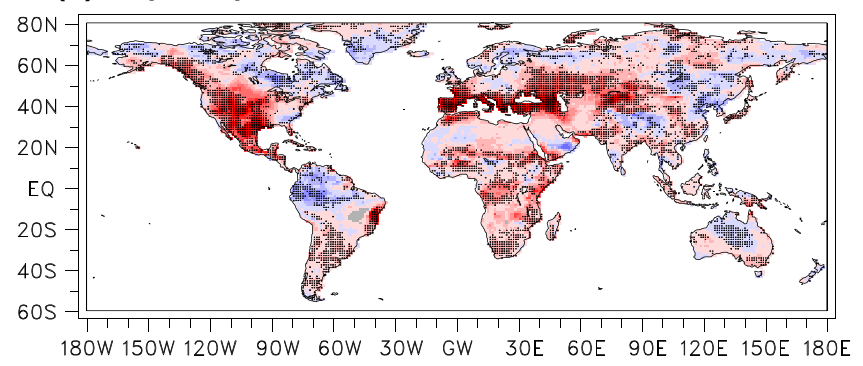

(f) ExpB-ExpA / fut / DJF

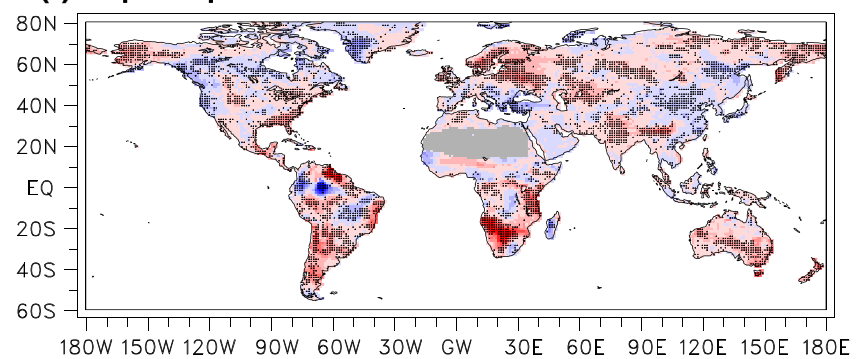

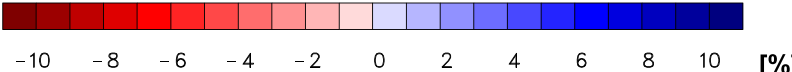

Fig. 7 As Fig. 6 but for the differences between ExpB and ExpA for 2056-2085. Grid points, where none of the five individual models has at least 30 wet days in either experiment during the respective season, are left in grey

(Fig. 7d) and the frequency of wet days (Fig. 7f) over most of the globe, but most pronounced in the Southern Hemisphere. Therefore, the soil moisture changes have a relatively strong impact on daily mean precipitation in the Southern Hemisphere (Fig. 7b). The impact of the soil moisture changes on the frequency of wet days is over many parts of the global land area coherent with the effect on latent heat flux (see Fig. 4c, d), except for tropical Africa, where the soil moisture differences lead to widespread increases in latent heat fluxes, while the frequency of wet days is reduced in much of the area (Fig. 7e, f).

Comparing the maps presented in Figs. 6 and 7 for the corresponding meteorological variable and season reveals that the projected differences in soil moisture contribute to 
the future changes in the characteristics of daily precipitation in some areas (where the differences presented in the corresponding maps have the same sign) but are offset by other processes in other areas (where the differences have opposite signs). In JJA, for instance, the soil moisture changes contribute to the decreases both in the frequency of wet days and in mean daily precipitation in the western part of North America, southern Europe, the southern part of South America or the southern parts of Southern Africa and Australia. In contrast, the decreases in all characteristics of daily precipitation associated with soil moisture in tropical Africa are offset by other process, leading to future increases in these meteorological variables in this region. In DJF, it is mainly in the Southern Hemisphere that the differences in soil moisture contribute to the future decreases both in the frequency of wet days and in mean daily precipitation, namely, in the southern part of South America, in Southern Africa and in Australia. Given the regionally varying sign of the changes in the intensity of wet days associated with the differences in soil moisture and the overall tendency of marked future increases in the intensity of daily precipitation in response to the anthropogenic climate forcing, particularly in DJF, the character of the contributions of the soil moisture differences to the changes in the intensity of daily precipitation is highly variable even at a regional scale.

The ensemble mean values of the SLR between the future changes in mean daily precipitation and the contributions from the differences in soil moisture confirm the notion that the impact of the soil moisture varies considerably by season in all nine regions (Fig. 8). In many seasons the slopes of the linear regression line are in the range between 0 and 1, but in a few cases the ensemble means are negative, i.e., the Mediterranean region in SON (Fig. 8c) as well as South Asia (Fig. 8e) and Western Africa (Fig. 8f) in AMJ, or exceed a value of 1 in several regions during part of the year. The few cases with negative SLRs illustrate the overall tendency that the differences in soil moisture contribute to the future changes in mean daily precipitation. In a number of cases, however, the projected future changes are stronger than the contributions from the soil moisture (indicated by SLRs exceeding 1). In all regions the contributions of the differences in soil moisture to the future changes in mean daily precipitation vary considerably in the course of the year. In Central Europe (Fig. 8b), for instance, the contributions are particularly strong in boreal spring and summer and rather weak in winter. Similarly, in the Mediterranean region (Fig. 8c) the contributions are particularly strong in boreal spring and summer and relatively weak in boreal autumn and early winter. In South Asia (Fig. 8e) as well as in Western Africa (Fig. 8f), the contributions are strongest during the summer monsoon season and boreal winter and weakest during the transition seasons. Amazonia (Fig. 8g) stands out as the region, where the differences in soil moisture typically give the weakest contributions to the future changes in mean daily precipitation over most of the year. Only in early austral summer, i.e., the early stage of the rainy season, the soil moisture differences give notable contributions to the future changes (indicated by SLRs in the range between 0.5 and 0.8 ).

The ensemble mean values of the SLR enclose marked variations between the individual models, including negative values or values exceeding 1.5 for one or several models. In a few cases, the SLRs for a single model exceed the potting range, indicating that either the future changes in daily mean precipitation have opposite signs as the contributions from soil moisture (exceeding -1) or they have the same sign but are much stronger than the contribution from soil moisture (exceeding 2). Such strong negative values are responsible for the three cases of negative ensemble mean values of the slopes, namely, in South Asia (Fig. 8e) and Western Africa (Fig. 8f) in AMJ as well as in the Mediterranean region (Fig. 8c) for SON, and for the small positive values in other cases. The most prominent cases are Amazonia (Fig. 8g) during late austral spring and summer, that is, the dry time of the year, the Mediterranean region (Fig. 8c) in boreal autumn and early winter or Northern Australia (Fig. 8i) in austral autumn.

Figure 9 shows the results from the linear regression analysis for the intensity of daily precipitation (marked in grey) and the frequency of wet days (marked in black) separately. As the changes in the frequency of wet days and the changes in the intensity of daily precipitation both contribute to the changes in mean daily precipitation, the diagrams display several of the features identified in Fig. 8. The ensemble mean values of the SLR are all positive for the intensity of daily precipitation and exceed a value of 1 only in a few cases, i.e., in Central North America (Fig. 9a) in AMJ as well as in Western Africa (Fig. 9f) and Southern Africa (Fig. 9h) in several seasons. This means that the soil moisture differences in all the cases presented here contribute to the future changes in the intensity of daily precipitation and that only in a few cases the projected changes are stronger than the contributions of the soil moisture. The situation is somewhat different for the frequency of wet days, for which a notably wider range of the ensemble mean values of the SLR is found. In several cases the slopes are negative, such as in Central Europe (Fig. 9b) in NDJ, the Mediterranean region (Fig. 9c) or Western Africa (Fig. 9f) in MJJ and particularly in boreal autumn. In some cases the values are only slightly larger than 0 , most prominently in Amazonia (Fig. 9g) in late austral autumn and Northern Australia (Fig. 9i) in austral autumn. On the other hand, there are also more cases with SLRs exceeding a value of 1, i.e., in Central North America (Fig. 9a) between late 
Mean daily precipitation - ExpB / fut-pre vs. ExpB-ExpA / fut

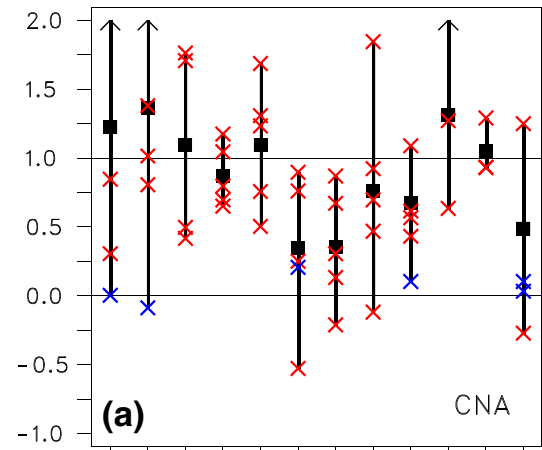

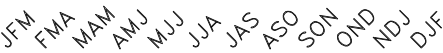

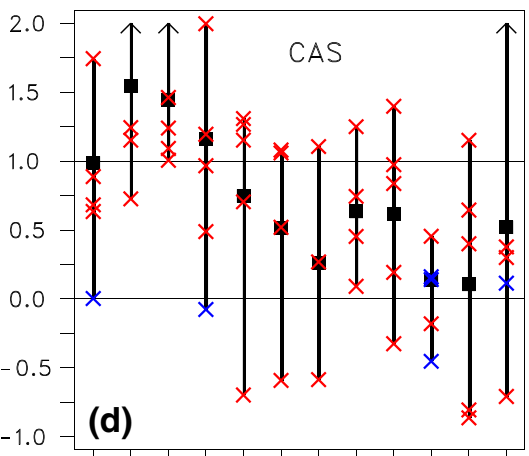

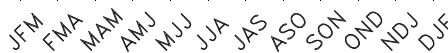

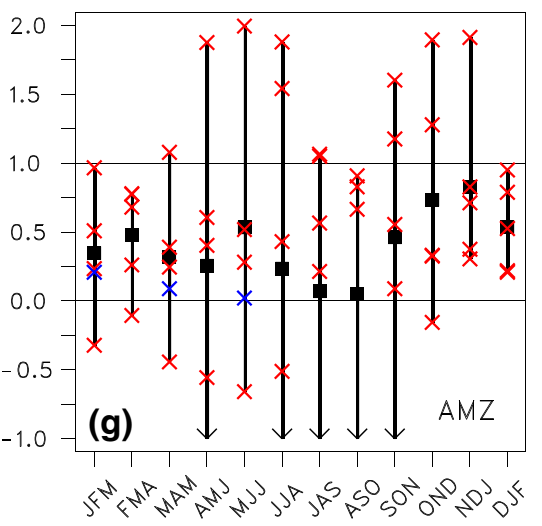

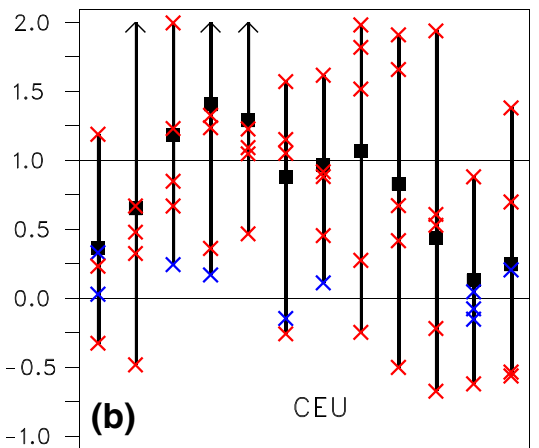

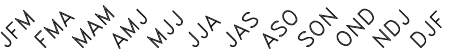

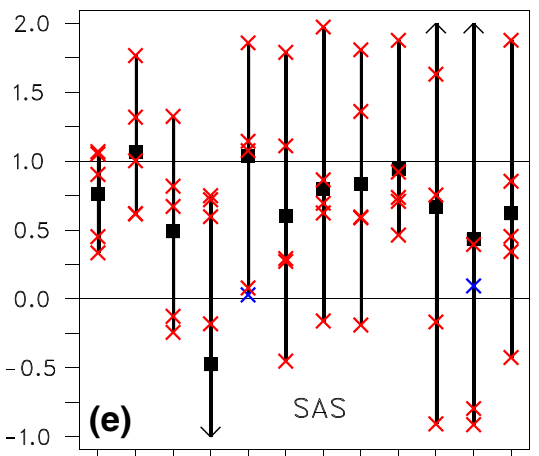

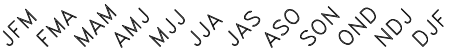

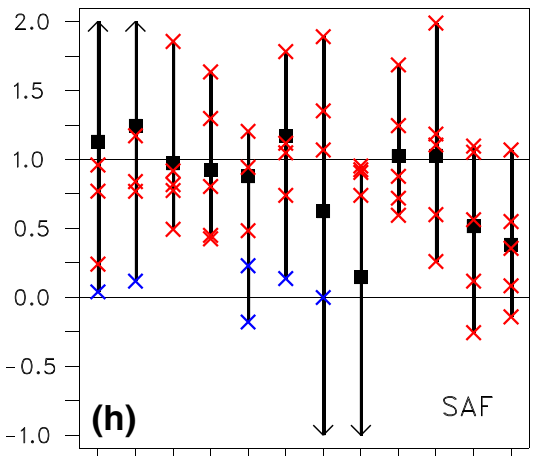

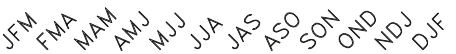

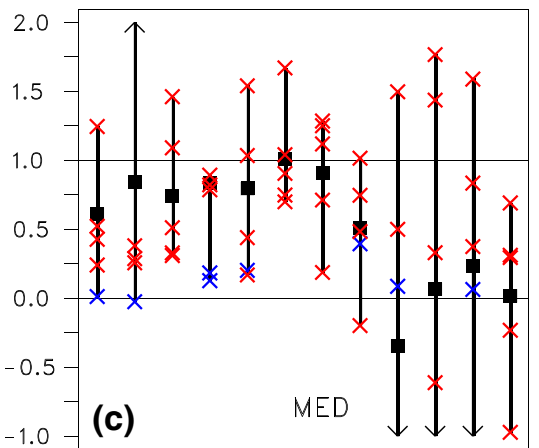

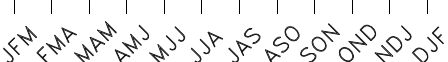

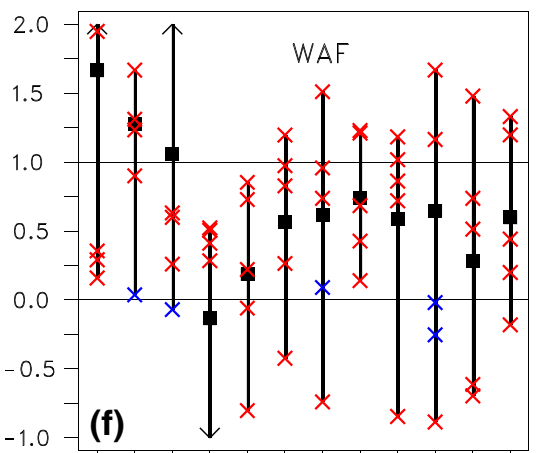

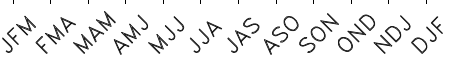

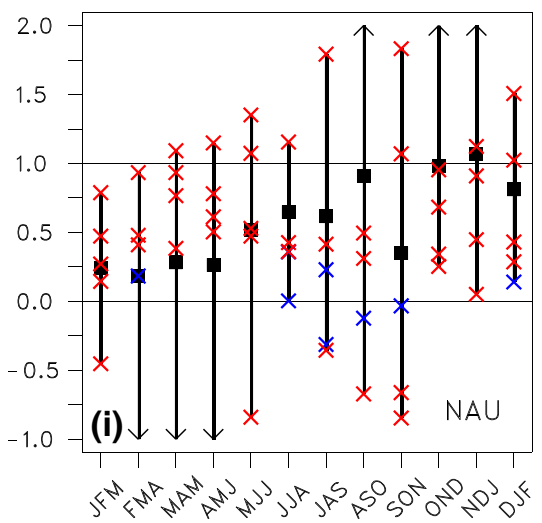

Fig. 8 As Fig. 5 but for seasonal mean daily precipitation. The statistics of daily precipitation has only been computed for grid points with at least 30 wet days for both the respective periods. Only grid points, where the differences between 2056-2085 and 1971-2000 for ExpB

boreal autumn and spring, Central Europe (Fig. 9b) and, to some extent, Central Asia (Fig. 9d) in boreal spring as well as South Asia (Fig. 9e) in boreal summer. The stronger seasonal variations of the ensemble means values of the SLR for the frequency of wet days as compared to the intensity of daily precipitation reflects the wider range between the SLRs for the individual models for the frequency of wet days in many regions. This includes the number of SLRs are significant at the $95 \%$ or the differences between ExpB and ExpA for 2056-2085 are significant at the 90\% level, respectively, are considered

exceeding the plotting range for individual models, which is notably higher for the frequency of wet days than for the intensity of daily precipitation. As for the intensity of daily precipitation, negative values exceeding -1 for a single model are only found in South Asia in JJA (Fig. 9e) and Amazonia in austral summer (Fig. 9g), and positive values exceeding 2 in Western Africa (Fig. 9f) in boreal spring and Southern Africa (Fig. 9h) in austral autumn. 
Wet day characteristics - ExpB / fut-pre vs. ExpB-ExpA / fut

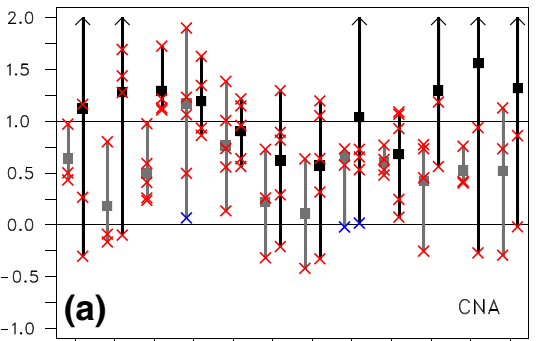

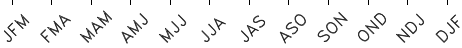

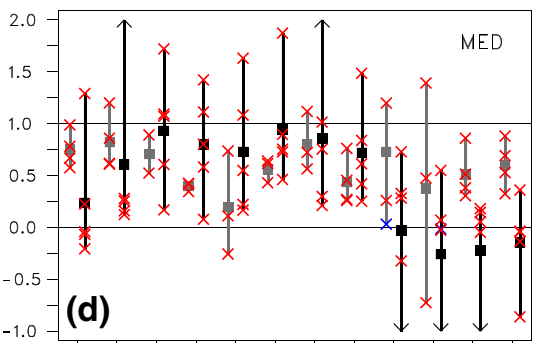

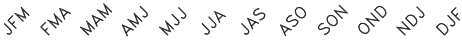

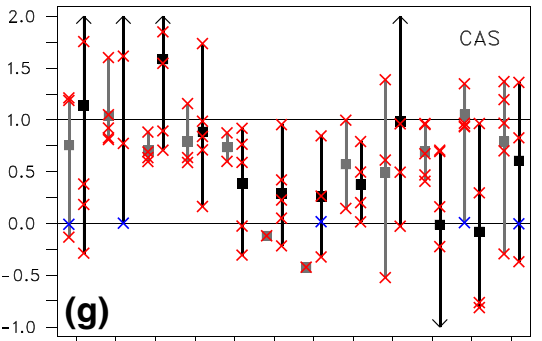

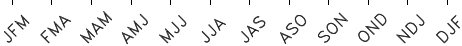
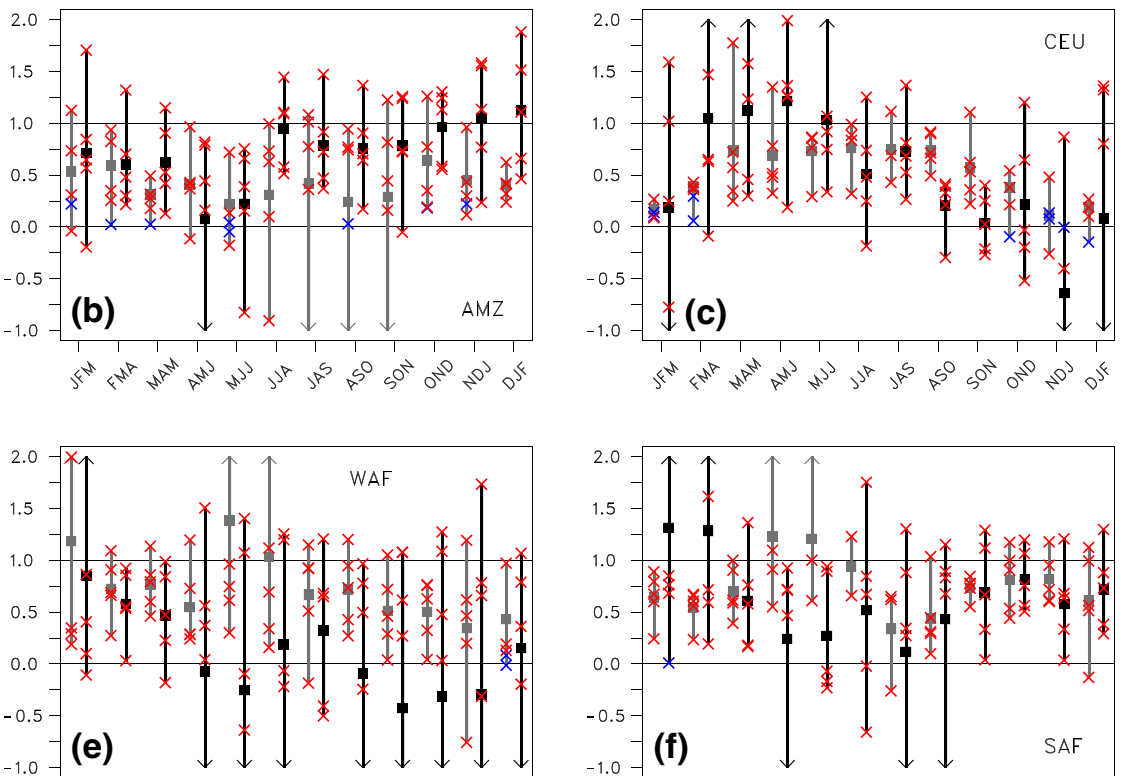

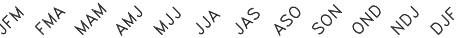

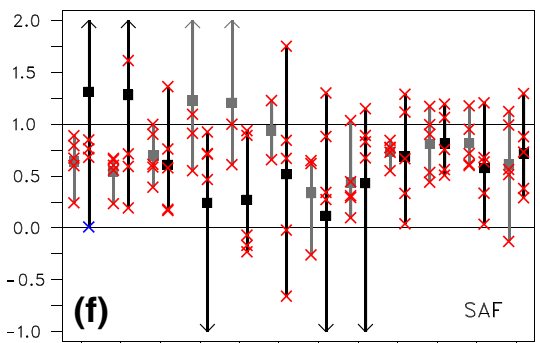

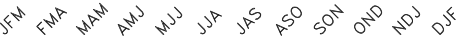
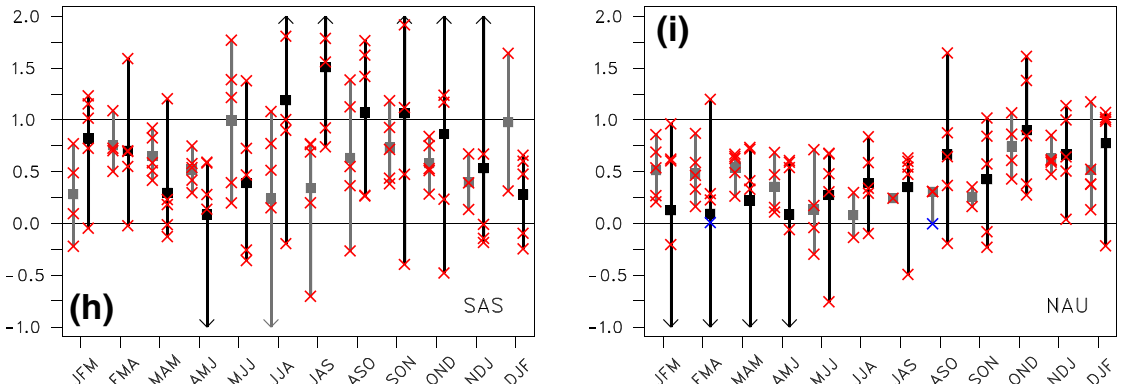

Fig. 9 As Fig. 8 but for the differences in the intensity of daily precipitation (grey), i.e., the average amount of precipitation on wet days, and the frequency of wet days (black)

\section{Wet and dry spell characteristics}

Wet and dry spells are defined as consecutive periods of wet days (days with at least $1 \mathrm{~mm}$ precipitation) and dry days (days with less than $1 \mathrm{~mm}$ precipitation), respectively. Here, wet spells with a length of at least four days and dry spells with a length of at least seven days are considered. Such wet spells can lead to large-scale flooding, while such dry spells can cause serious droughts. Two characteristics of wet and dry spells are described here, i.e., their frequency and the median of their length. In order to avoid that a few wet or dry spells dominate the statistics, we have only analysed grid points with at least five extended wet or dry periods, respectively. In the geographical distributions to be presented in the following, these regions (more precisely, the regions where none of the five individual models has sufficient wet or dry spells) are marked in grey.

\subsection{Wet spells}

Both the frequency (Fig. 10a, b) and the length of wet spells (Fig. 10c, d) are characterised by notable future changes in response to the anthropogenic forcing. In DJF, for instance, the frequency of wet spells is distinctly increased in the mid- and high latitudes of the Northern Hemisphere, along the Guinea coast and in Eastern Africa as well as in the areas south of the equator in South America and Africa and over the Malay Archipelago (Fig. 10b). The length of wet spells, on the other hand, is decreased in the areas south of the equator in South America and over the Malay Archipelago and markedly increased along the Guinea coast and in Eastern Africa (Fig. 10d). In JJA the length of wet spells is decreased over much of the global land area. Considerable reductions are found in Central America, in Western and Eastern Africa north of the equator as well as in South Asia 
(a) ExpB / fut-pre / JJA

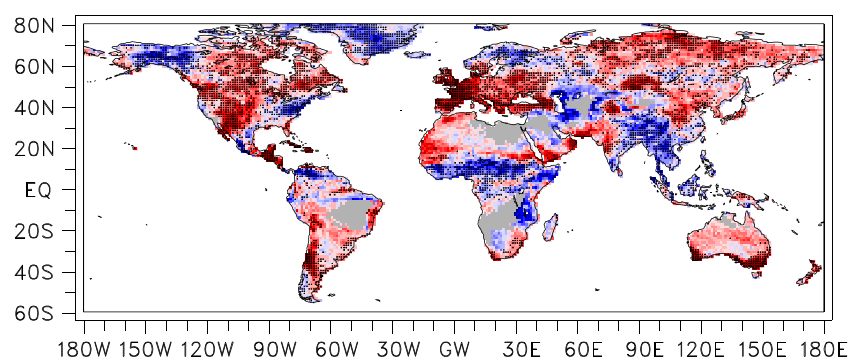

\section{Frequency of wet spells}

(b) ExpB / fut-pre / DJF

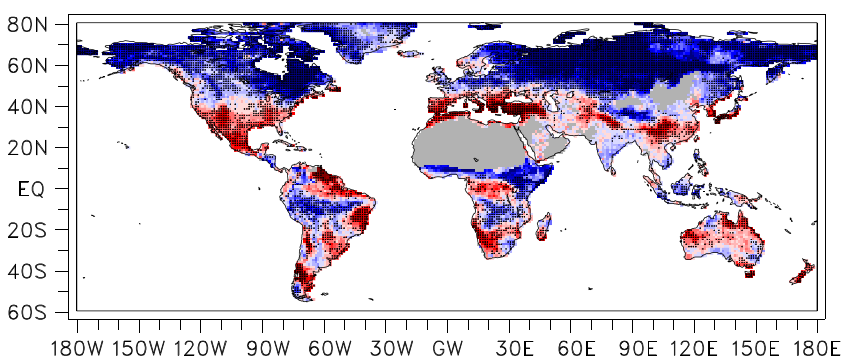

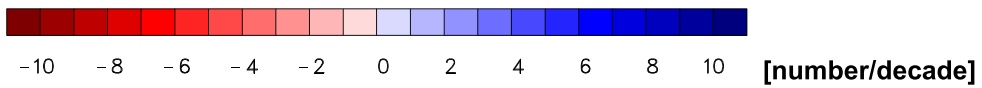

Median length of wet spells

(c) ExpB / fut-pre / JJA

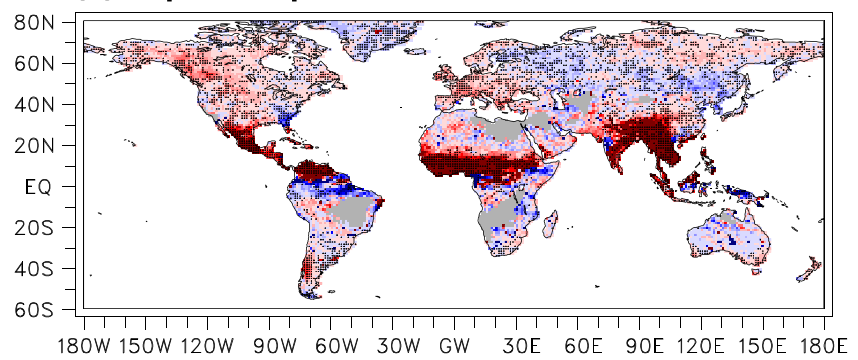

(d) ExpB / fut-pre / DJF

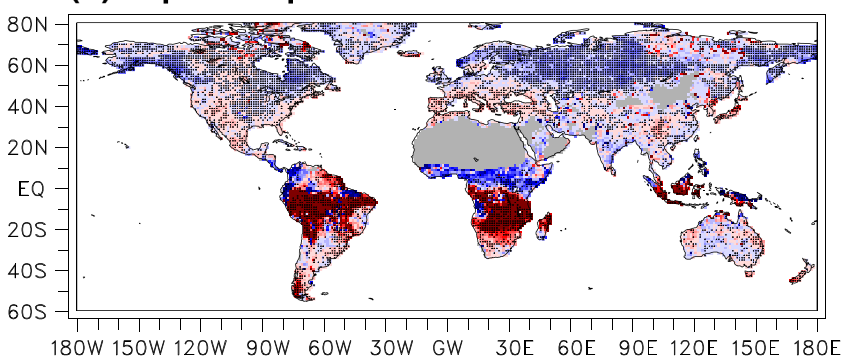

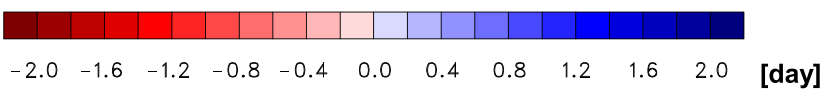

Fig. 10 Differences in the frequency of wet spells of at least 4 days (upper row) and the median of the length of these wet spells (lower row) between 2056-2085 and 1971-2000 for ExpB in (a, c) boreal summer (JJA) and (b, d) austral summer (DJF), averaged over the five climate models. Grid points, where none of the five individual models has at least 5 such wet spells in either period during the respective season, are left in grey. The black dots indicate, where at least four of the five models agree on the sign of the differences. Units are number/decade $(\mathbf{a}, \mathbf{b})$ and day $(\mathbf{c}, \mathbf{d})$; the contour intervals are $1 /$ decade $(\mathbf{a}, \mathbf{b})$ and 0.2 day $(\mathbf{c}, \mathbf{d})$, respectively

are reflected in corresponding decreases in the length of wet spells.

In JJA the projected differences in soil moisture have a general tendency to contribute to the future changes in the characteristics of wet spells (Fig. 11a, c), with increases and decreases in both the frequency and the length of wet spells in many of the same regions (see Fig. 10a, c). In DJF, on the other hand, such a general tendency can only be identified in the Southern Hemisphere, where the soil moisture changes (Fig. 11b, d) generally contribute to the notable decreases in both the frequency and length of wet spells (see Fig. 10b, d). Similar to the projected future changes, the effects of the soil moisture on the wet spell characteristics reflect to some extent the corresponding impacts on the frequency of wet days (see Fig. 7e, f). In JJA, for instance, the decreases in the frequency of wet spells and the somewhat weaker decreases in the length of wet spells in much of the Northern Hemisphere extratropics are associated with notable decreases in the frequency of wet days. while the prominent decreases in parts of Northern Africa 


\section{Frequency of wet spells}

(a) ExpB-ExpA / fut / JJA

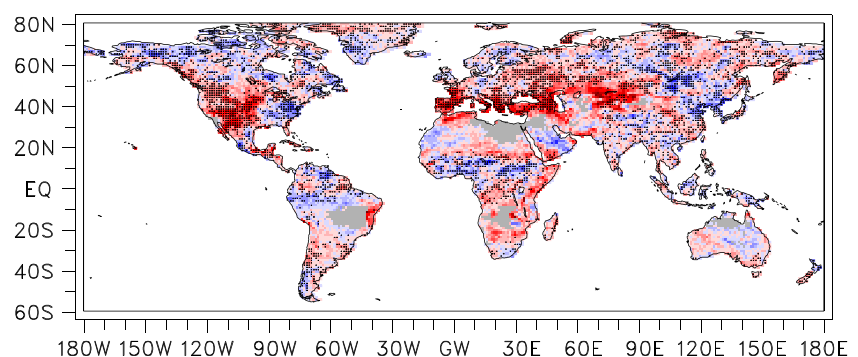

(b) ExpB-ExpA / fut / DJF

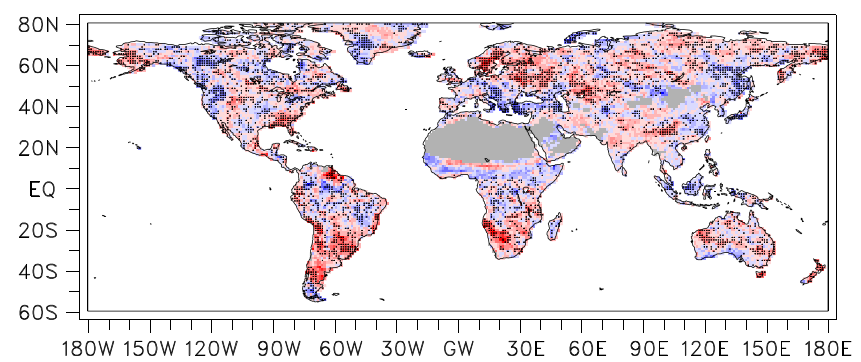

\begin{tabular}{lll|l|l|l|l|l|l|l|l|l|lll}
\hline & & & & & & & & & & & & & & \\
-10 & -8 & -6 & -4 & -2 & 0 & 2 & 4 & 6 & 8 & 10 & [number/decade]
\end{tabular}

Median length of wet spells

(c) ExpB-ExpA / fut / JJA

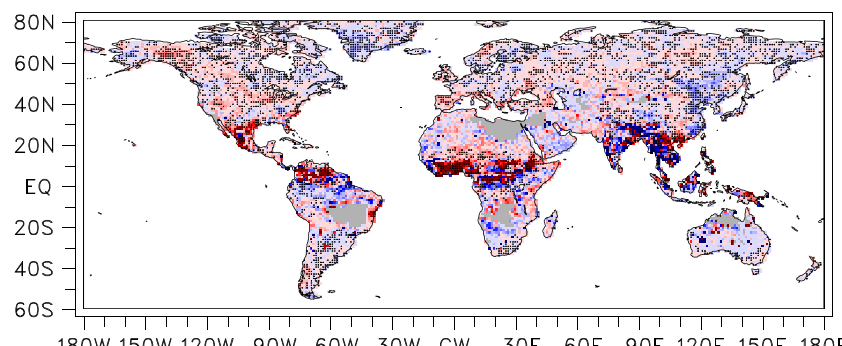

(d) ExpB-ExpA / fut / DJF

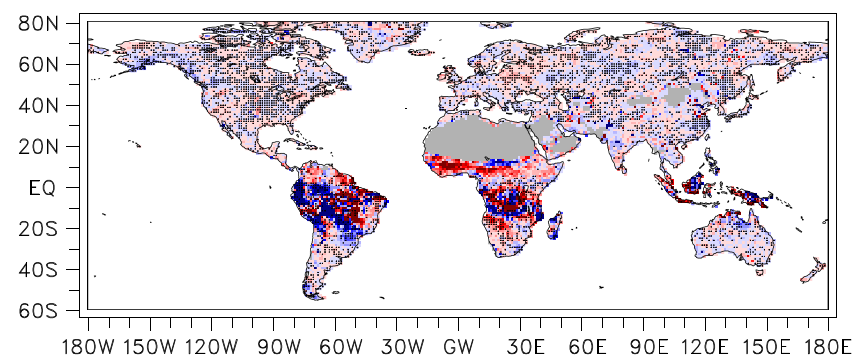

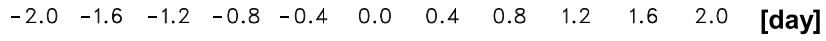

Fig. 11 As Fig. 10 but for the differences between ExpB and ExpA for 2056-2085. Grid points, where none of the five individual models has at least 5 wet spells in either experiment during the respective season, are left in grey

Likewise, in DJF, the decreases in the frequency of wet days over the southern part of South America and in Southern Africa are reflected in corresponding decreases in the frequency of wet spells.

The ensemble mean values of the SLR (Fig. 12) confirm the general tendency that the differences in soil moisture contribute to the future changes in the two characteristics of wet spells, with the majority of the values in the range between 0.3 and 0.8 . In several regions the SLRs vary in the course of the year. In the Mediterranean region (Fig. 12c), for instance, the slopes are rather small in early boreal winter and large in spring and summer. In Central North America (Fig. 12a), on the other hand, the SLRs are relatively large during the transition seasons and small in boreal summer and winter, while in South Asia (Fig. 12e) the values of the SLR are particularly large in boreal summer. The seasonal variations in the contributions of the differences in soil moisture to the future changes in the frequency and the length of wet spells in these regions correspond to the seasonal variations in the contributions of the differences in soil moisture to the future changes in the frequency of wet days (see Fig. 9). There is a tendency of stronger variations between the individual models for the contributions to the changes in the frequency of wet spells than for the contributions to the changes in their length. In particular, the majority of the few cases with negative contributions of the soil moisture to the future changes or with especially strong positive contributions (with SLRs exceeding a value of 2) by a single model are found for the frequency of wet spells.

\subsection{Dry spells}

Figures 13 and 14 show the future changes in the characteristics of dry spells and the contributions of the differences in soil moisture, respectively. In these two figures we have reversed the colour schemes, with red (blue) colours for positive (negative) differences, corresponding to dryer (wetter) conditions. 
Wet spell characteristics - ExpB / fut-pre vs. ExpB-ExpA / fut
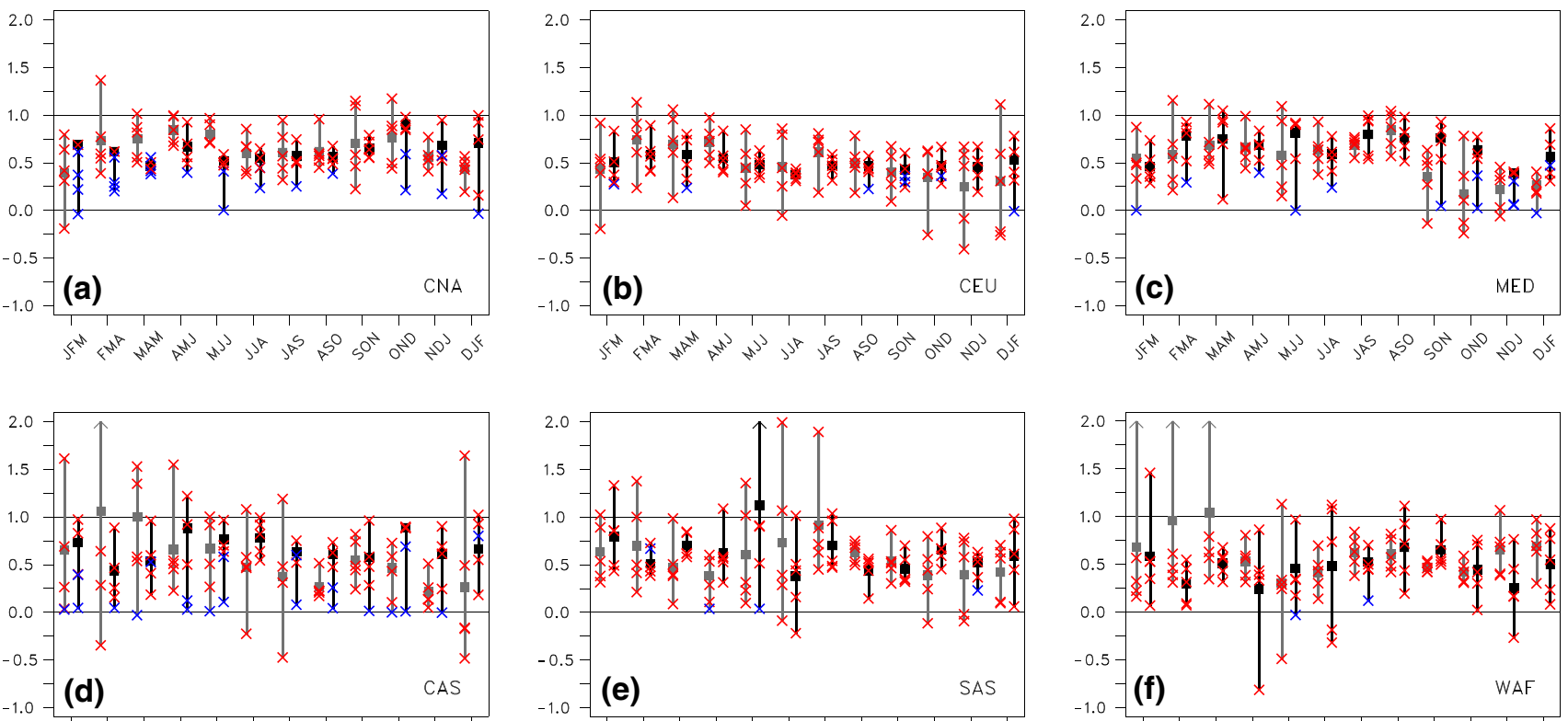

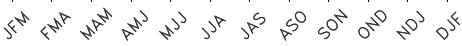

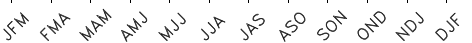

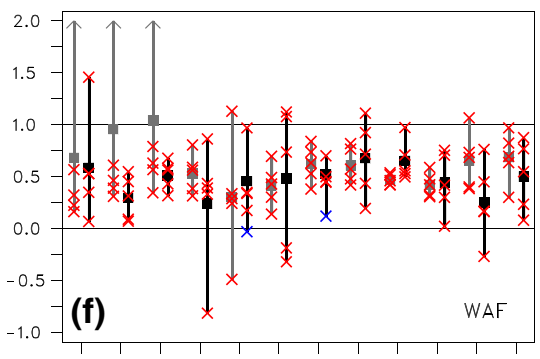

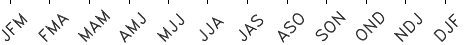
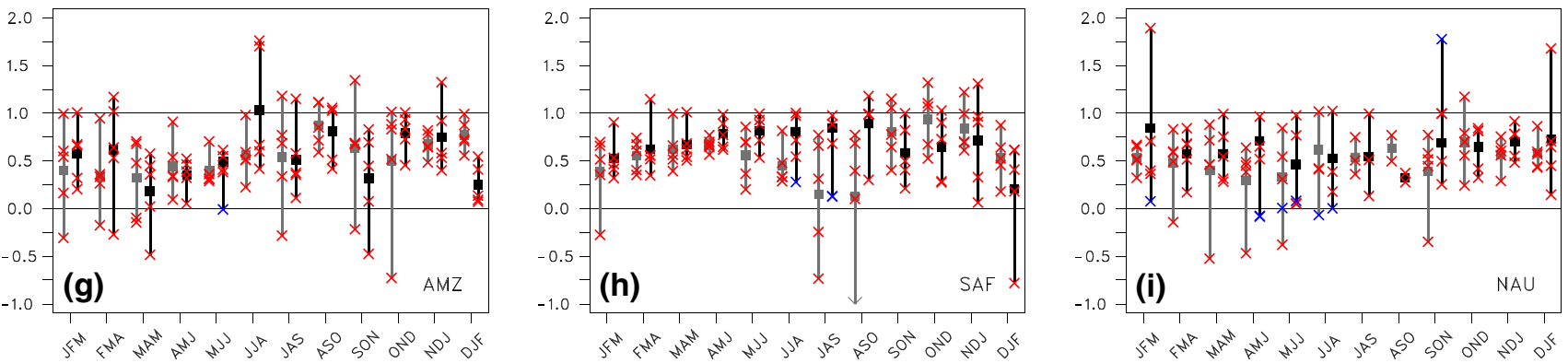

Fig. 12 As Fig. 9 but for the differences in various characteristics of wet spells of at least 4 days, i.e., the frequency (grey) and the median length of these wet spells (black). The statistics of the wet spells has

The future changes in the frequency of dry spells in response to the anthropogenic forcing are closely related to the corresponding changes in the frequency of wet spells over most of the global land area. The frequency of dry spells is typically decreased (increased) in areas with an increasing (decreasing) frequency of wet spells. In DJF, for instance, the frequency of dry spells is notably increased in the southern parts of North America and Europe as well as in South America and in Africa south of the equator but decreased in the mid- and high latitudes in the Northern Hemisphere (Fig. 13b). In JJA the frequency of dry spells is increased over much of the Northern Hemisphere extratropics but decreased over much of the Southern Hemisphere (Fig. 13a). In both seasons the length of dry spells is increased in the subtropics in both hemispheres, extending into the southern parts of North America and Europe in JJA (Fig. 13c), and is decreased in the mid- and high latitudes in only been computed for grid points with at least 5 such spells for both the respective periods

the Northern Hemisphere (particularly in eastern Asia) and in Eastern Africa in DJF (Fig. 13d). The projected changes in soil moisture lead to notable increases in the length of dry spells in the subtropics in both hemispheres (Fig. 14c, d), with a tendency of more pronounced increases in the respective summer hemisphere. By this, soil moisture contributes to the future increases in the length of dry spells in these regions. The soil moisture also contributes to the future changes in the frequency of dry spells in various regions (Fig. 14a, b), but the magnitude of the changes associated with the differences in soil moisture is notably smaller than the magnitude of the future changes in the frequency of dry spells.

Similar to the wet spells, the ensemble mean values of the SLR (Fig. 15) affirm the notion that the differences in soil moisture generally contribute to the future changes in the two characteristics of dry spells, with the majority of 
(a) ExpB / fut-pre / JJA

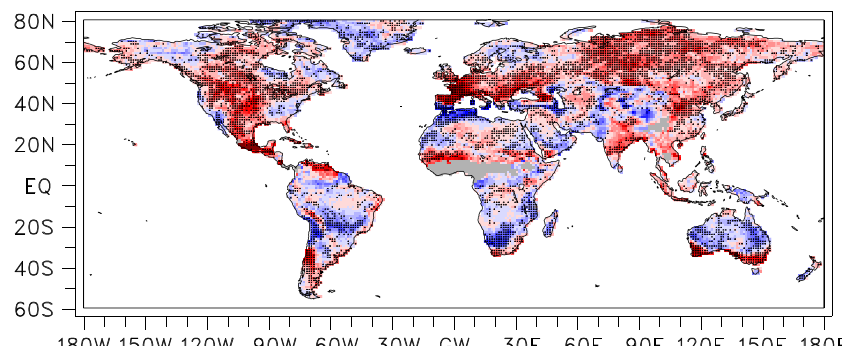

\section{Frequency of dry spells}

(b) ExpB / fut-pre / DJF

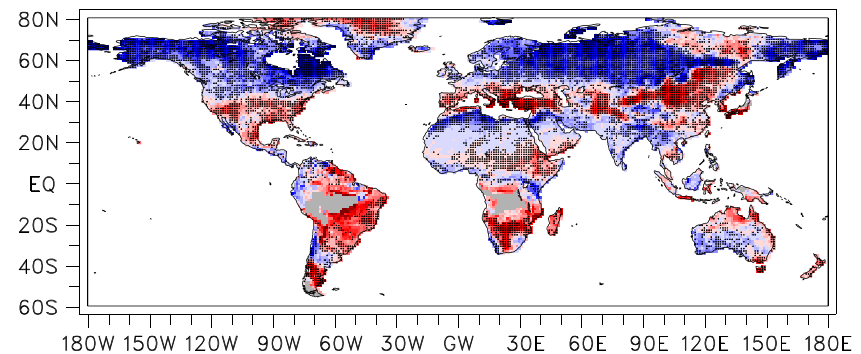

(c) ExpB / fut-pre / JJA

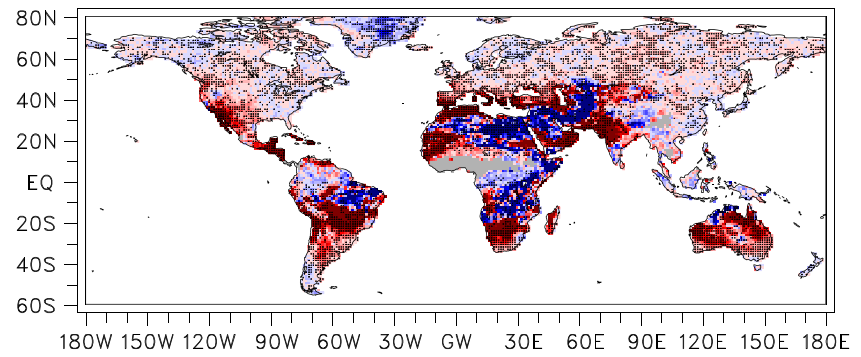

\section{Median length of dry spells}

(d) ExpB / fut-pre / DJF

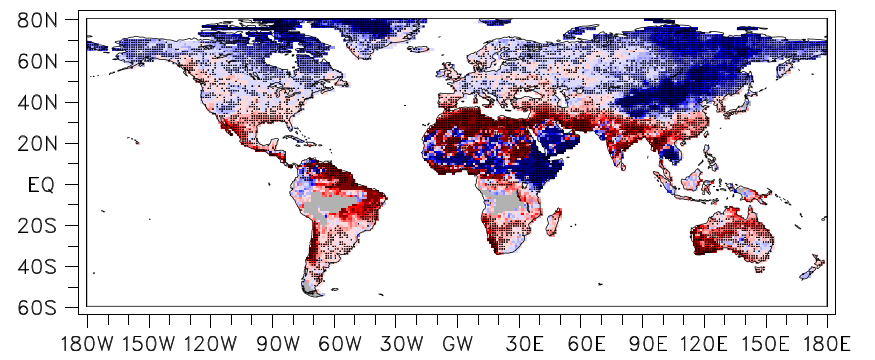

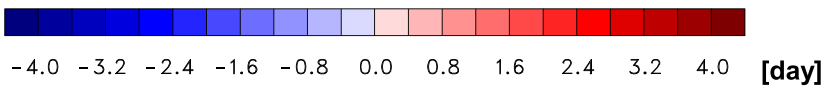

Fig. 13 As Fig. 10 but for dry spells of at least 7 days. Grid points, where none of the five individual models has at least 5 such dry spells in either period during the respective season, are left in grey. In this case, the contour interval for the median of the length is 0.4 day (c,

the values in the range between 0.2 and 1 . The seasonal variations of these values, which occur in some regions, follow by and large the corresponding variations identified for the wet spells. The range of the deviations between the individual models is typically somewhat larger than for the wet spells. In particular, there are more cases with representative negative values of the SLR for single models, i.e., in Western Africa for boreal summer and autumn (Fig. 15e) or in South Asia for boreal autumn and winter (Fig. 15e).

\section{Discussion}

As mentioned in Sect. 1, Seneviratne et al. (2010) introduced a conceptual framework for the soil moisture-precipitation coupling and feedback, comprising of three links: first, a relationship between soil moisture anomalies and subsequent evapotranspiration anomalies, second, a relationship between evapotranspiration anomalies and subsequent precipitation anomalies and, finally, a relationship d). Also note the reversed colour schemes with different shades of red (blue) for positive (negative) differences, corresponding to dryer (wetter) conditions

between precipitation anomalies and resulting soil moisture anomalies. The first two connections constitute the soil moisture-precipitation coupling and the full loop with all the three components the soil moisture-precipitation feedback. For the third link, increasing precipitation generally causes increased soil moisture, although some exceptions occur (see Sect. 1 for further details). The first relationship is generally positive, with higher soil moisture leading to stronger evapotranspiration, with a particularly strong positive effect on evaporation in the transitional zones between dry and wet climates. The direction of the second step, however, is the most uncertain as several physical processes are involved (see Sect. 1 for further details).

In our study on the contributions of soil moisture interactions to future precipitation changes we have analysed the nature of these three relationships from the long-term perspective of projected climate changes in response to the anthropogenic climate forcing. To begin with, the five climate models contributing to the GLACE-CMIP5 experiment simulate pronounced future changes in soil moisture, 
(a) ExpB-ExpA / fut / JJA

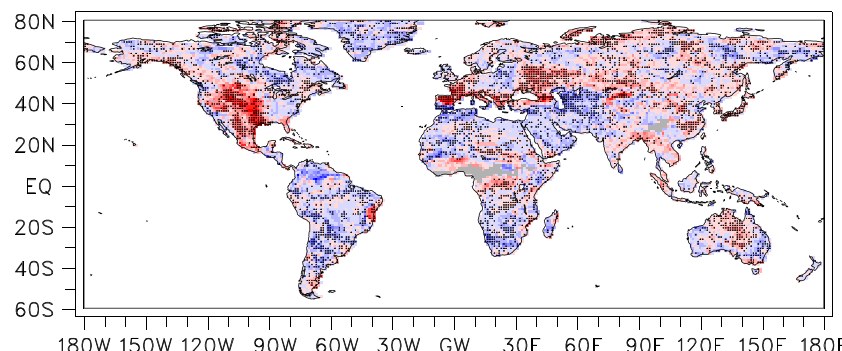

\section{Frequency of dry spells}

(b) ExpB-ExpA / fut / DJF

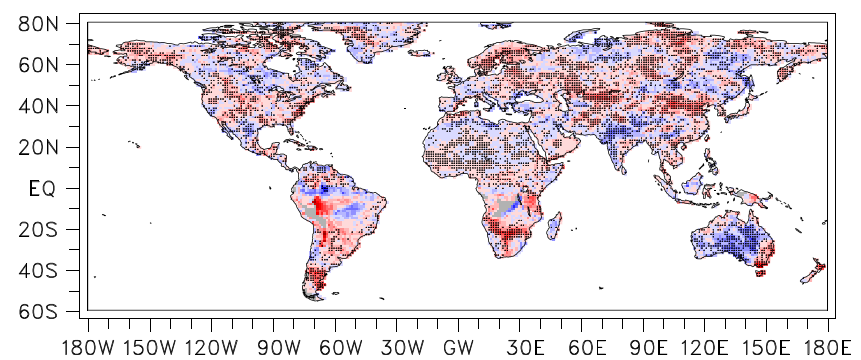

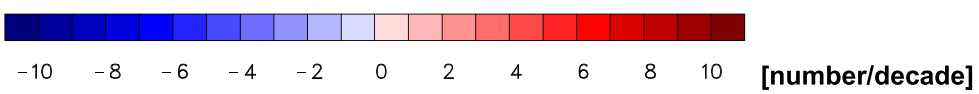

\section{Median length of dry spells}

(c) ExpB-ExpA / fut / JJA

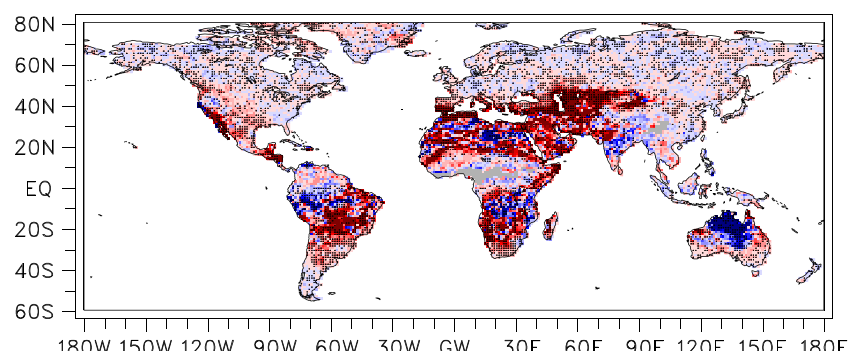

(d) ExpB-ExpA / fut / DJF

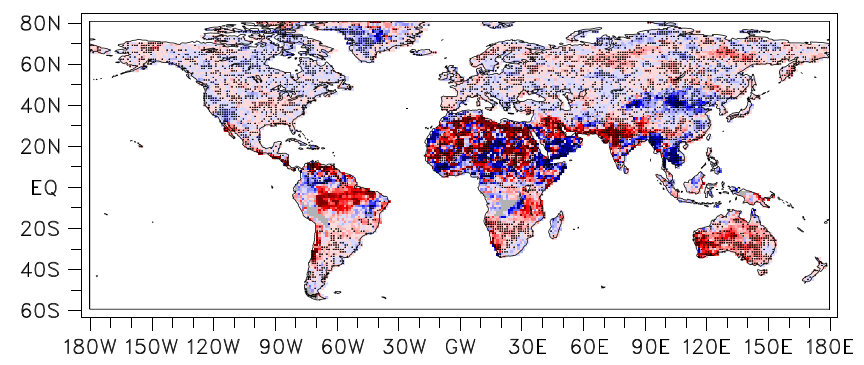

$\begin{array}{llllllllllll}-4.0 & -3.2 & -2.4 & -1.6 & -0.8 & 0.0 & 0.8 & 1.6 & 2.4 & 3.2 & 4.0 & \text { [day] }\end{array}$

Fig. 14 As Fig. 13 but for the differences between ExpB and ExpA for 2056-2085. Grid points, where none of the five individual models has at least 5 wet spells in either experiment during the respective season, are left in grey

which are generally similar to the corresponding results both from the CMIP3 multi-model ensemble (Wang 2005; Orlowsky and Seneviratne 2012) and from the complete CMIP5 multi-model ensemble (Orlowsky and Seneviratne 2013). These changes in soil moisture are found to be mainly driven by the projected changes in mean daily precipitation, confirming the positive coupling between precipitation and soil moisture, that is, the third relationship in the aforementioned conceptual framework. These changes in soil moisture lead to marked changes in latent heat flux, again, confirming the strong positive coupling between soil moisture and evaporation, namely, the first relationship. The changes in the latent heat flux associated with the differences in soil moisture are found to govern the projected future changes in latent heat flux.

The contribution of the differences in soil moisture and, thus, in evaporation to the future changes in mean daily precipitation is not as clear, namely, weaker and not as robust. Although this second link of the conceptual framework is found to be generally positive with predominantly increases (decreases) in precipitation in areas with increasing (decreasing) soil moisture, the strength and, in some cases, also the sign of this coupling varies by region and, in particular, by season. This discrepancy is consistent with Wei and Dirmeyer (2012), who investigated the mechanisms governing the impact of soil moisture on precipitation by dissecting the coupling into the ability of soil moisture to affect evapotranspiration and into the ability of evapotranspiration to affect precipitation. They found that the coupling between soil moisture and evapotranspiration is characterized as a local process, while the coupling between evapotranspiration and precipitation also includes non-local atmospheric processes. The non-local processes tend to reduce the contributions of the differences in soil moisture to the future precipitation changes in areas, where soil moisture notably contributes to the future changes in latent heat fluxes.

The contributions of the differences in soil moisture to the future changes are found to vary between the intensity of daily precipitation and the frequency of wet days, as they are stronger and more robust for the frequency of wet days. This is mainly because the differences in soil moisture lead 
Dry spell characteristics - ExpB / fut-pre vs. ExpB-ExpA / fut

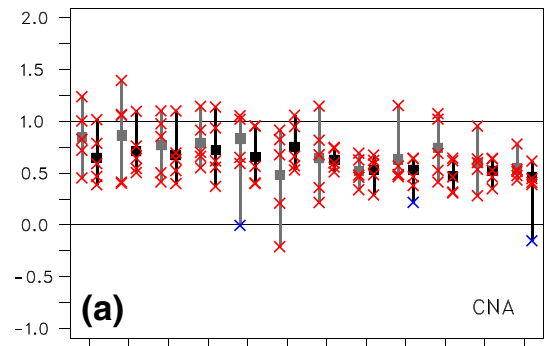

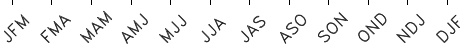

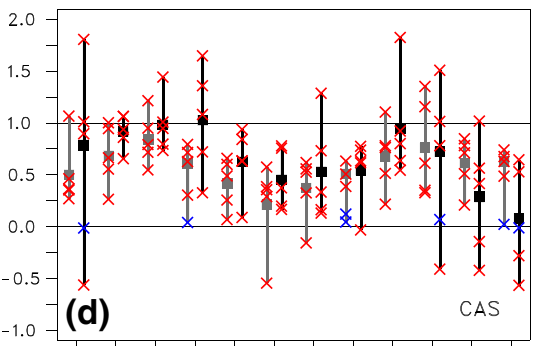

scis

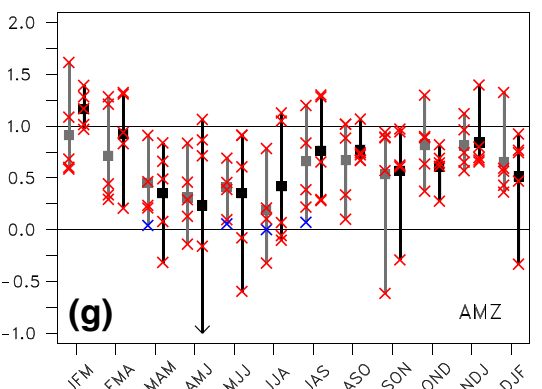

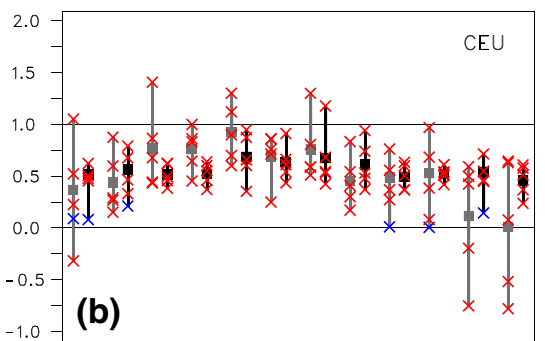

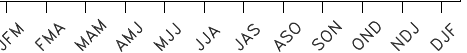

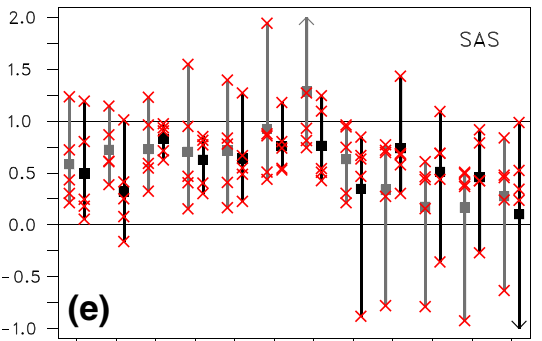

sरs

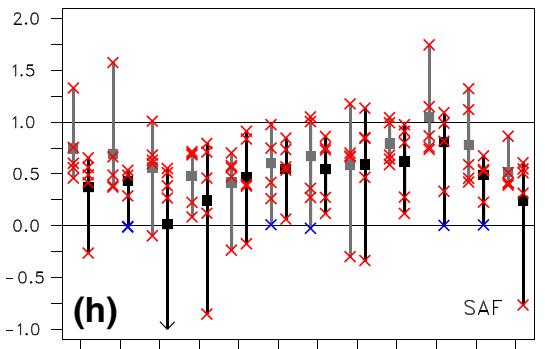

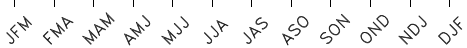

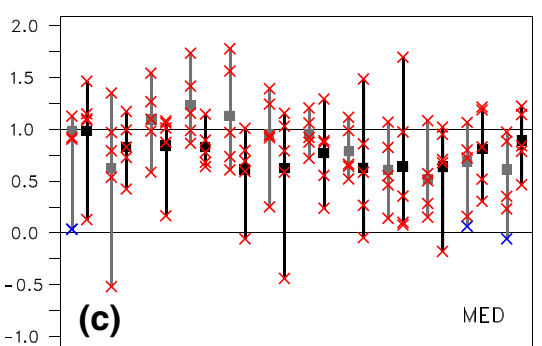

scis
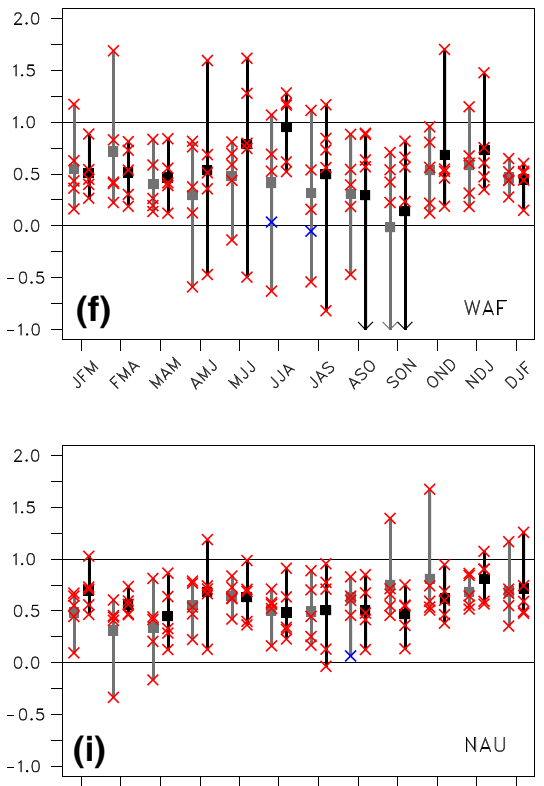

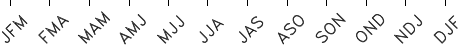

Fig. 15 As Fig. 12 but for dry spells of at least 7 days

to consistent, both positive and negative, changes in both characteristics of daily precipitation, while the signs of the future changes differ considerably between them. Consistent with the contributions of the differences in soil moisture to the future changes in the frequency of wet days, soil moisture generally contributes to the future changes in both the frequency and length of extended wet and dry spells. The magnitude of these contributions does not differ systematically between these two aspects of the spells, but the contributions are generally slightly stronger for dry spells than for wet spells. The results are supported by the findings of Lorenz et al. (2016), who investigated the effect of future soil moisture changes on the maximum number of consecutive wet and dry days, respectively, on an annual basis. In particular, they found reductions in the maximum length of wet spells and increases in the maximum length of dry spells predominantly in areas with decreasing soil moisture.

\section{Conclusions}

In the present study we have extended the methodology defined and used in May et al. (2015) to quantify the contributions of soil moisture interactions to the future changes in climate in several ways. Here we include, for instance, a different set of meteorological variables. In addition to latent heat flux and mean daily precipitation, we consider two characteristics of daily precipitation (the frequency of wet days and the intensity of daily precipitation) as well as two characteristics of extended wet and dry spells (the frequency and the median length of these spells). Also, we here consider the near-global land areas, while our previous study focused on the tropics. Most importantly, we also put focus on regional as well as seasonal variations of the magnitude of the contributions of the projected differences in soil moisture to the future changes in the various 
meteorological variables. For this, we have selected nine regions covering different parts of the globe.

Our analysis reveals the overall tendency that the projected differences in soil moisture contribute to the future changes in response to the anthropogenic climate forcing for all the meteorological variables considered here. These contributions are stronger (the magnitude of the contributions is defined via a linear regression analysis) and more robust (illustrated by the variations between the individual climate models) for the latent heat flux than for the characteristics of daily precipitation. This is consistent with the fact that the soil moisture anomalies affect latent heat flux directly via evapotranspiration, while the impact on precipitation is less direct. This is because the occurrence and intensity of precipitation is not only governed by the local changes in atmospheric moisture associated with variations in evapotranspiration but also changes in the stability of the atmospheric boundary layer or in the cloudiness as well as variations of the atmospheric circulation. The results also show that the contributions of the differences in soil moisture to the future changes are generally stronger and more robust for the frequency of wet days than for the intensity of daily precipitation. The latter is mainly due to the fact that the differences in soil moisture lead to consistent, both positive and negative, changes in these two characteristics of daily precipitation, while the signs of the future changes differ considerably between the two variables with increases in the intensity of daily precipitation over much of the global land area. Consistent with the contributions of the projected differences in soil moisture to the future changes in the frequency of wet days, soil moisture generally contributes to the future changes in the characteristics of wet and dry spells. The magnitude of these contributions does not differ systematically between the frequency and the length of such extended spells, but the contributions are generally slightly stronger for dry spells than for wet spells.

Distinguishing between the nine selected regions and between the different seasons, we find that the strength of the contributions of the differences in soil moisture to the future changes in the various meteorological variables varies by region and, in particular, by season. Similarly, the robustness of these contributions, i.e., the agreement between the individual climate models, varies between the regions and in the course of the year. These variations emphasize the relevance of regional analyses of the soil moisture-precipitation coupling under consideration of the entire annual cycle. Such regional studies would also allow for addressing the specific atmospheric conditions and characteristic flow patterns, such as the summer monsoon circulations in West Africa or South Asia, which might affect the coupling between soil moisture anomalies and precipitation. Given the importance of soil moisture for the future changes in various aspects of the hydrological cycle and other aspects of climate, which have not been analysed here, such regional studies based on a variety of climate models could lead to a better understanding of the deviations between the regional climate changes simulated by these models (e.g., Knutti and Sedláček 2012).

The evidence that the projected differences in soil moisture give notable contributions to the future changes in several meteorological variables, which describe aspects of the hydrological cycle, also demonstrates the importance of a comprehensive and realistic representation of land surface processes and of land surface conditions in climate models. This calls for the inclusion of advanced land surface schemes (van den Hurk et al. 2016) and fully coupled dynamic vegetation models in climate models as well as for the prescription of anthropogenic land use changes (Lawrence et al. 2016). The consideration of these elements will contribute to more realistic climate simulations and to more reliable future climate scenarios.

Acknowledgements The research presented in this paper is a contribution to the Swedish strategic research area ModElling the Regional and Global Earth system, MERGE. Thanks to the modelling groups at GFDL (Kirsten Findell) and NCAR (David Lawrence) for sharing the data from their GLACE-CMIP5 simulations, people at ETHZ (Sonia Seneviratne and Martin Hirschi) for coordinating the GLACE-CMIP5 experiment and their help with the data and Alexis Berg for helpful comments on an earlier version of the manuscript. We also thank the anonymous reviewers for their comments and suggestions that helped to improve the manuscript.

Open Access This article is distributed under the terms of the Creative Commons Attribution 4.0 International License (http://creativecommons.org/licenses/by/4.0/), which permits unrestricted use, distribution, and reproduction in any medium, provided you give appropriate credit to the original author(s) and the source, provide a link to the Creative Commons license, and indicate if changes were made.

\section{References}

Berg A et al (2015) Interannual coupling between summertime surface temperature and precipitation over land: processes and implications for climate change. J Clim 28:1308-1328. doi:10.1175/ JCLI-D-14-00324.1

Berg A et al (2016) Land-atmosphere feedbacks amplify aridity increase over land under global warming. Nat Clim Change 6:869-874. doi:10.1038/NCLIMATE3029

Bras RD (1990) Hydrology: an introduction to hydrologic science. Addison-Wesley, USA, p 643

Ek MB, Holtslag AAM (2004) Influence of soil moisture on boundary layer cloud development. J Hydrometeorol 5:86-99

Findell KL, Eltahir EAB (2003) Atmospheric controls on soil moisture-boundary layer interactions. Part II: feedbacks within the continental United States. J Hydrometeorol 4:570-583

Findell KL, Gentine P, Lintner BR, Kerr C (2011) Probability of afternoon precipitation in eastern United States and Mexico enhanced by high evaporation. Nat Geosci 4:434-439. doi:10.1038/NGEO1174 
Guillod BP, Orlowsky B, Miralles DG, Teuling AJ, Seneviratne SI (2015) Reconciling spatial and temporal soil moisture effects on afternoon rainfall. Nat Commun 6:6443. doi:10.1038/ ncomms7443

Hillel D (1998) Environmental soil physics. Acadamic Press, USA, p 771

Hohenegger C, Brockhaus P, Bretherton C, Schär C (2009) The soil moisture-precipitation feedback in simulations with explicit and parameterized convection. J Clim 22:5003-5020. doi:10.1175/2 009JCLI2604.1

Knutti R, Sedláček J (2012) Robustness and uncertainties in the new CMIP5 climate model projections. Nat Clim Change 3:369373. doi:10.1038/NCLIMATE1716

Koster RD et al (2004) Regions of strong coupling between soil moisture and precipitation. Science 305:1138-1140. doi:10.1126/ science. 1100217

Koster RD et al (2010) Contribution of land surface initialization to subseasonal forecast skill: first results from a multi-model experiment. Geophys Res Lett 37:L02402. doi:10.1029/200 9GL041677

Lawrence DM et al (2016) The Land Use Model Intercomparison Project (LUMIP) contribution to CMIP6: rationale and experimental design. Geosci Model Dev 9:2973-2998. doi:10.5194/ gmd-9-2973-2016

Lorenz R et al (2016) Influence of land-atmosphere feedbacks on temperature and precipitation extremes in the GLACE-CMIP5 ensemble. J Geophys Res 121:607-623. doi:10.1002/201 5JD024053

May W, Meier A, Rummukainen M, Berg A, Chéruy F, Hagemann S (2015) Contributions of soil moisture interactions to climate change in the tropics in the GLACE-CMIP5 experiment. Clim Dyn 45:3275-3297. doi:10.1007/s00382-015-2538-9

Moss RH et al (2010) The next generation of scenarios for climate change research and assessment. Nature 463:747-756. doi:10.1038/nature08823

Orlowsky B, Seneviratne SI (2012) Global changes in extreme events: regional and seasonal dimension. Clim Change 110:669-696. doi:10.1007/s10584-011-0122-9

Orlowsky B, Seneviratne SI (2013) Elusive drought: uncertainty in observed trends and short- and long-term CMIP5 projections. Hydrol Earth Syst Sci 17:1765-1781. doi:10.5194/ hess-17-1765-2013
Pal JS, Eltahir EAB (2001) Pathways relating soil moisture conditions to future summer rainfall within a model of the land-atmosphere system. J Clim 14:1227-1242

Riahi K et al (2011) RCP 8.5-A scenario of comparatively high greenhouse gas emissions. Clim Change 109:33-57. doi:10.1007/s10584-011-0149-y

Schär C, Lüthi D, Beyerle U, Heise E (1999) The soil-precipitation feedback: a process study with a regional climate model. J Clim $12: 722-741$

Seneviratne SI, Corti T, Davin EL, Hirschi M, Jaeger EB, Lehner I, Orlowsky B, Teuling AJ (2010) Investigating soil moisture-climate interactions in a changing climate: a review. Earth Sci Rev 99:125-161. doi:10.1016/j.earscirev.2010.02.004

Seneviratne SI et al (2012) Changes in climate extremes and their impacts on the natural physical environment. In: Field CB, Barros V, Stocker TF, Qin D, Dokken DJ, Ebi KL, Mastrandrea MD, Mach KJ, Plattner G-K, Allen SK, Tignor M, Midgley PM (eds) Managing the risks of extreme events and disasters to advance climate change adaptation. Cambridge University Press, Cambridge, pp 109-230

Seneviratne SI et al (2013) Impact of soil moisture-climate feedbacks on CMIP5 projections: first results from the GLACE-CMIP5 experiments. Geophys Res Lett 40:5212-5217. doi:10.1002/ grl.50956

Taylor CM, de Jeu RAM, Guichard F, Harris PP, Dorigo WA (2012a) Afternoon rain more likely over drier soils. Nature 489:423426. doi:10.1038/nature11377

Taylor KE, Stouffer RJ, Meehl GA (2012b) An overview of CMIP5 and the experiment design. Bull Am Meteorol Soc 93:485-498. doi:10.1175/BAMS-D-11-00094.1

Van den Hurk B et al (2016) LS3MIP (v1.0) contribution to CMIP6: the Land Surface, Snow and Soil moisture Model Intercomparison Project-aims, setup and expected outcome. Geosci Model Dev 9:2809-2832. doi:10.5194/gmd-9-2809-2016

Wang G (2005) Agricultural drought in a future climate: results from 15 global climate models participating in the IPCC 4th assessment. Clim Dyn 25:739-753. doi:10.1007/s00382-005-0057-9

Wei J, Dirmeyer PA (2012) Dissecting soil moisture-precipitation coupling. Geophys Res Lett 39:L19711. doi:10.1029/201 2GL05303816702 